\title{
SUPLEMENTAÇÃO DIETÉTICA DE VITAMINA C, DESENVOLVIMENTO E SANIDADE DO PACU \\ (Piaractus mesopotamicus Holmberg, 1887)
}

\section{GERALDO SILVA DE CAMPOS ALMEIDA}

\begin{abstract}
Dissertação apresentada à Escola Superior de Agricultura "Luiz de Queiroz", Universidade de São Paulo, para obtenção do título de Mestre em Agronomia, Área de Concentração: Ciência Animal e Pastagens.
\end{abstract}

P I R A C I C A B A

Estado de São Paulo - Brasil

Outubro - 2003 


\title{
SUPLEMENTAÇÃO DIETÉTICA DE VITAMINA C, DESENVOLVIMENTO E SANIDADE DO PACU \\ (Piaractus mesopotamicus Holmberg, 1887)
}

\author{
Geraldo Silva de CAMPoS AlMEIDA \\ Engenheiro Agrônomo
}

\section{Orientador: Prof. Dr. JOSÉ EURICO POSSEBON CYRINO}

Dissertação apresentada à Escola Superior de Agricultura "Luiz de Queiroz", Universidade de São Paulo, para obtenção do título de Mestre em Agronomia, Área de Concentração: Ciência Animal e Pastagens.

P I R A C I C A B A

Estado de São Paulo - Brasil

Outubro - 2003 


\section{Dados Internacionais de Catalogação na Publicação (CIP) DIVISÃO DE BIBLIOTECA E DOCUMENTAÇÃO - ESALQ/USP}

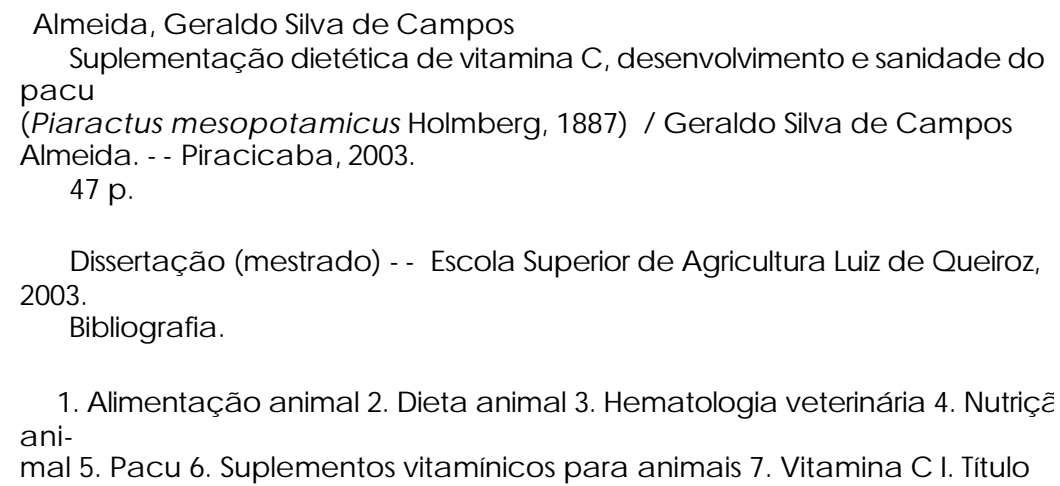

CDD 639.375 


\section{DEDICATÓRIA}

Dedico e ofereço este trabalho a minha querida esposa e minha filha

\section{Andréa e Carolina}

e a meus pais e minha irmã,

Tharcizio, Elysia e Mariana

Pelo incentivo, ajuda e amor de todos 


\section{AGRADECIMENTOS}

A Deus, por dar-me apoio em todos os momentos.

Ao Departamento de Produção Animal da ESALQ/USP, pela oportunidade de realizar este trabalho e a todos os professores, pelos ensinamentos e amizade.

Ao Prof. Dr. José Eurico Possebon Cyrino, pela oportunidade, confiança, orientação, incentivo, serenidade e pela amizade em todos os momentos.

Aos Profs. Drs. Luiz Edivaldo Pezzato e Margarida M. Barros e sua equipe do Laboratório de Nutrição de Organismos Aquáticos (FMVZ-UNESP, Botucatu), pela amizade, auxílio e disponibilização dos equipamentos para o preparo das rações experimentais.

À Profa. Dra. Elisabeth C. Urbinati e sua equipe do Laboratório de Morfologia e Fisiologia Animal (FCAV-UNESP, Jaboticabal) e ao CAUNESP, pela disponibilidade e auxílio na realização das análises hematológicas.

Ao Prof. Dr. Frab Norberto Bóscolo e sua equipe do Departamento de Radiologia da Faculdade de Odontologia de Piracicaba (FOP-UNICAMP), pela amizade e disponibilidade na realização dos exames radiológicos.

À SupreMais Produtos Bioquímicos Ltda. e BASF S.A., pela doação de ingredientes para o preparo das rações experimentais.

À minha querida esposa Andréa e minha filha Carolina e a toda minha família, por toda a atenção, incentivo, amor e compreensão, sempre.

Ao pesquisador Dr. Rodrigo O. de Almeida Ozório, pelos ensinamentos e ajuda na realização deste trabalho e pela amizade construída.

À FAPESP, pela concessão da bolsa de estudos. 
Aos colegas do Setor de Piscicultura, Ana Maria, Cristina, Leandro, Luciane, Jony, Jussiara, Sílvio, aos estagiários, aos técnicos Ismael Baldessin Júnior e Sérgio Vanderlei Pena e aos demais funcionários do Departamento de Produção Animal da ESALQ, pela amizade e apoio na condução dos trabalhos.

Agradeço aos demais colegas do curso e a todos que, de alguma forma, contribuíram para a realização deste trabalho. 


\section{SUMÁRIO}

Página

LISTA DE TABELAS .............................................................................. vii

LISTA DE FIGURAS ................................................................................ viii

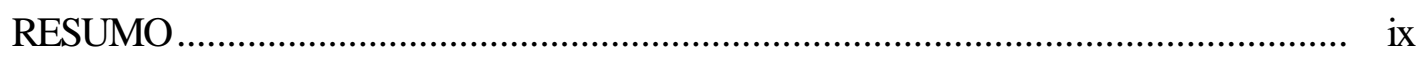

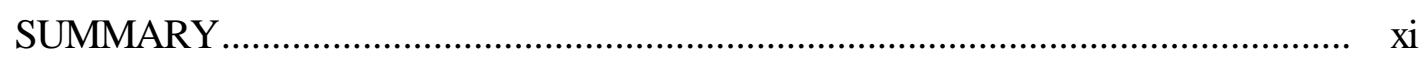

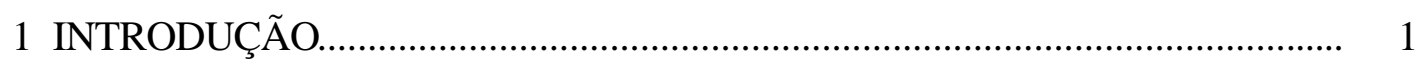

2 REVISÃO DE LITERATURA ......................................................................... 3

2.1 A aqüicultura e a espécie............................................................................. 3

2.2 Metabolismo e nutrição ........................................................................... 5

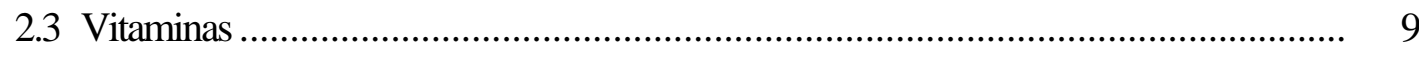

2.4 Vitamina $\mathrm{C}$ na nutrição de peixes ......................................................................... 11

3 MATERIAL E MÉTODOS .......................................................................... 16

4 RESULTADOS E DISCUSSÃO _................................................................. 21

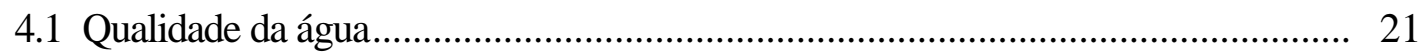

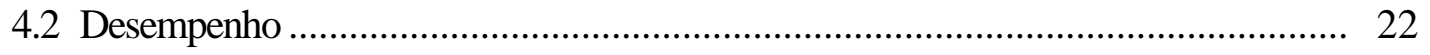

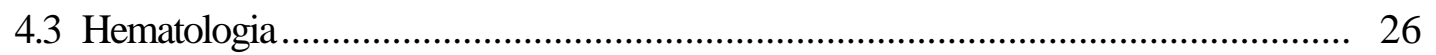

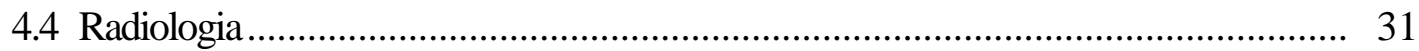

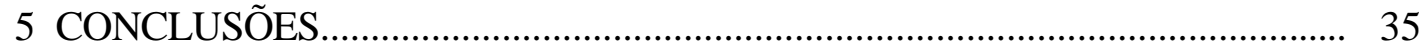

REFERÊNCIAS BIBLIOGRÁFICAS _......................................................... 36

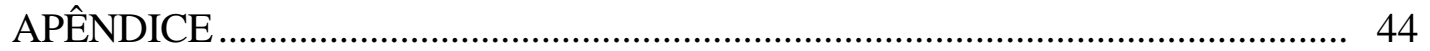




\section{LISTA DE TABELAS}

Página

1 Composição das dietas experimentais $(\%)$............................................................ 17

2 Composição nutricional das dietas calculada ......................................................... 18

3 Médias dos parâmetros de qualidade da água durante o experimento ........................ 22

4 Médias das variáveis de desempenho analisadas para os tratamentos........................ 23

5 Médias dos parâmetros hematológicos analisados para os tratamentos ...................... 27 


\section{LISTA DE FIGURAS}

Página

1 Regressões para as médias de peso final (PF), em função do nível de vitamina $\mathrm{C}$ na dieta: (A) não-linear segmentada, (B) linear...

2 Regressão polinomial para as médias de ganho de peso (GDP) dos peixes em resposta aos diferentes níveis de vitamina $\mathrm{C}$ na dieta

3 Regressões para as médias de conversão alimentar (CA), em função do nível de vitamina $\mathrm{C}$ na dieta: (A) não-linear segmentada, (B) linear.

4 Regressão polinomial para as médias de contagem de eritrócitos (GV) dos peixes em resposta aos diferentes níveis de vitamina $\mathrm{C}$ na dieta.

5 Regressões para as médias de hematócrito (HCT), em resposta aos níveis de vitamina $\mathrm{C}$ na dieta: (A) não-linear segmentada, (B) quadrática.

6 Regressão não-linear segmentada para as médias de volume corpuscular médio (VCM), em resposta aos níveis de vitamina $\mathrm{C}$ na dieta.

7 Regressão polinomial para as médias de hemoglobina $(\mathrm{Hb})$ em resposta aos níveis de vitamina $\mathrm{C}$ na dieta.

8 Radiografias de alevino de pacu

9 Radiografias de alevino de pacu com incidência de anquilose entre vértebras torácicas. 


\title{
SUPLEMENTAÇÃO DIETÉTICA DE VITAMINA C, DESENVOLVIMENTO E SANIDADE DO PACU (Piaractus mesopotamicus Holmberg, 1887)
}

\author{
Autor: GERALDO SILVA DE CAMPOS ALMEIDA \\ Orientador: Prof. Dr. JOSÉ EURICO POSSEBON CYRINO
}

\section{RESUMO}

O pacu, Piaractus mesopotamicus Holmberg, 1887 (Characiformes, Characidae), é uma das principais espécies da fauna aquática brasileira, com grande potencial para aqüicultura interior. Estudos sobre nutrição e determinação de exigências nutricionais são ferramentas para embasar a formulação de dietas completas e consolidar a piscicultura intensiva e viável da espécie. A suplementação dietética com vitamina $\mathrm{C}$ tem importância na eficiência alimentar, sanidade dos estoques e na economicidade das dietas e da criação. $\mathrm{O}$ objetivo deste projeto foi determinar as exigências nutricionais em vitamina $\mathrm{C}$ de alevinos de pacu. Os peixes $(9,06 \pm 1,40 \mathrm{~g})$ foram alimentados com dietas contendo diferentes teores de vitamina $\mathrm{C}$, ad libitum, duas vezes ao dia, durante 63 dias, e avaliados quanto ao desempenho, medido pelo ganho de peso (GDP), consumo de ração, conversão alimentar (CA), taxa de crescimento específico (TCE) e sanidade, considerando-se a incidência de sinais de deficiência em vitamina $\mathrm{C}$ e alterações hematológicas - contagem de eritrócitos (GV), hematócrito (HCT), hemoglobina $(\mathrm{Hb})$, volume corpuscular médio (VCM) e leucócitos totais (GB). As rações semipurificadas foram suplementadas com dez níveis de inclusão: 0 (controle), 50, 100, 150, 200, 250, 300, 500, 700 e $900 \mathrm{mg}$ de vitamina C (monofosfato de ácido ascórbico) $\mathrm{kg}^{-1}$, em 
delineamento inteiramente ao acaso, com quatro repetições por ratamento. O efeito dos níveis de vitamina $\mathrm{C}$ sobre as variáveis foi analisado por regressão polinomial linear e regressão não-linear segmentada, para a determinação de valores ótimos de suplementação. A análise das variáveis de desempenho não detectou diferença entre os tratamentos $(\mathrm{P}>0,05)$. As regressões para peso final $(\mathrm{PF})$ e GDP indicaram tendência linear positiva com maiores doses de vitamina $\mathrm{C}$ e o nível ótimo estimado para PF foi de 423,1 mg de vitamina $\mathrm{C} \mathrm{kg}^{-1}$. O ganho de peso relativo médio dos tratamentos foi de $460,8 \%$. Houve efeito linear negativo das doses de vitamina $\mathrm{C}$ sobre as médias de CA ( $\mathrm{P}=0,038)$ e foi determinado o valor de $635,7 \mathrm{mg} \mathrm{kg}^{-1}$ de dieta no ponto de quebra $(\mathrm{P}=0,068)$. $\mathrm{O}$ valor médio de $\mathrm{CA}$ para os tratamentos foi de 0,95 . As médias de TCE não diferiram $(\mathrm{P}>0,05)$ e o valor médio encontrado foi de $2,72 \%$ dia $^{-1}$. As médias das variáveis hematológicas não diferiram $(\mathrm{P}>0,05)$. A $\mathrm{GV}$ teve efeito linear negativo na regressão com o aumento da vitamina $\mathrm{C}$ na dieta $(\mathrm{P}<0,05)$. Foi encontrado efeito quadrático $(\mathrm{P}=0,024)$ para o HCT na regressão linear e o valor ótimo determinado pela regressão não-linear segmentada foi de $254,0 \mathrm{mg} \mathrm{kg}^{-1}$. Existiu fraca evidência linear positiva para os dados de VCM na análise de regressão não-linear segmentada ( $\mathrm{P}=0,090$ ), com valor estimado de $109,7 \mathrm{mg}$ de vitamina $\mathrm{C} \mathrm{kg}^{-1}$ de dieta no ponto de quebra. Houve fraca evidência linear negativa na regressão para as médias de $\mathrm{Hb}$ $(\mathrm{P}=0,103)$ e as médias de contagem de leucócitos totais $(\mathrm{GB})$ não diferiram $(\mathrm{P}>0,05)$. Os exames radiológicos não detectaram deformidades estruturais nos peixes analisados. $\mathrm{O}$ nível de 254,0 mg de vitamina $\mathrm{C} \mathrm{kg}^{-1}$ de dieta foi suficiente para garantir a sanidade e desempenho adequados para o pacu. 


\title{
DIETARY VITAMIN C SUPPLEMENTATION, GROWTH AND HEALTH OF PACU (Piaractus mesopotamicus Holmberg, 1887)
}

\author{
Author: GERALDO SILVA DE CAMPOS ALMEIDA \\ Adviser: Prof. Dr. JOSÉ EURICO POSSEBON CYRINO
}

\section{SUMMARY}

The pacu Piaractus mesopotamicus Holmberg, 1887 (Characiformes, Characidae), is one of the main species of the Brazilian aquatic fauna with great potential for inland aquaculture. Studies on nutritional requirements of the species are important tools to establish the basis for the formulation of complete diets and consolidate the intensive and viable farming of the species. Dietary vitamin $\mathrm{C}$ supplementation plays an important role in feed efficiency, sanity of the stocks and economical viability of fish diets. The objective of this study was to determine nutritional requirements of vitamin $\mathrm{C}$ of fingerling pacu $(9.06 \pm 1.40 \mathrm{~g})$, fed diets containing different levels of vitamin $\mathrm{C}$, ad libitum, twice a day for 63 days, through the performance indexes weight gain (WG), feed consumption, feed conversion rate (FCR), specific growth rate (SGR); sanity through incidence of vitamin $\mathrm{C}$ deficiency signals, and hematological analyses - red blood cells counting (RBC), hematocrit (HCT), hemoglobin $(\mathrm{Hb})$, mean corpuscular volume (MCV), and total white blood cells counting (WBC). Semi-purified diets were supplemented with 0 (control), 50, 100, 150, 200, 250, 300, 500, 700, and $900 \mathrm{mg}$ of vitamin C (ascorbic acid monophosphate) $\mathrm{kg}^{-1}$, and fed to fish in a totally randomized design with four replicates. Effects of dietary 
levels of vitamin $\mathrm{C}$ on performance parameters were analyzed by linear polynomial regression and non-linear segmented regression. No differences were detected among treatments $(\mathrm{P}>0.05)$. Regression analysis for final weight $(\mathrm{FW})$ and $\mathrm{WG}$ indicated positive, linear tendency with larger vitamin $\mathrm{C}$ doses, the best level for FW being 423.1 $\mathrm{mg}$ of vitamin $\mathrm{C} \mathrm{kg}^{-1}$ diet. The average relative weight gain of fish was $460.8 \%$. There was linear, negative effect of vitamin $\mathrm{C}$ doses on the averages FCR $(\mathrm{P}=0.038)$, reaching the break point at $635.7 \mathrm{mg}$ vitamin $\mathrm{C} \mathrm{kg}^{-1}$ diet $(\mathrm{P}=0.068)$, and average $\mathrm{FCR}=0.95$ for all treatments. The average SGR $\left(2.72 \%\right.$ day $\left.^{-1}\right)$ did not differ among treatments $(\mathrm{P}>0.05)$. Averages of hematological variables did not differ $(\mathrm{P}>0.05)$. RBC had negative linear effect with increasing dietary vitamin $\mathrm{C}(\mathrm{P}<0.05)$. A quadratic effect was determined for HCT ( $\mathrm{P}=0.024)$; the break point of the non-linear segmented regression was $254.0 \mathrm{mg}$ vitamin $\mathrm{C} \mathrm{kg}^{-1}$ diet. There was a low, positive linear evidence for MCV $(\mathrm{P}=0.090)$, the break point standing at $109.7 \mathrm{mg}$ of vitamin $\mathrm{C} \mathrm{kg}^{-1}$ of diet. There was low, negative linear evidence for average $\mathrm{Hb}(\mathrm{P}=0.103)$, and the averages for $\mathrm{WBC}$ did not differ $(\mathrm{P}>0.05)$ among treatments. Radiological exams did not detect structural deformities in the analyzed fish. The level of $254.0 \mathrm{mg}$ vitamin $\mathrm{C} \mathrm{kg}^{-1}$ diet was enough to allow sanity and appropriate performance of fingerling pacu. 


\section{INTRODUÇÃO}

O pacu, Piaractus mesopotamicus Holmberg, 1887 (Characiformes, Characidae), é uma das principais espécies da fauna aquática brasileira. Características como rusticidade, crescimento rápido e facilidade em aceitar ração, bem como potencial para pesca esportiva e carne muito bem aceita pelo mercado consumidor tornaram o pacu uma espécie importante para aqüicultura interior (Brener, 1988; Carneiro, 1983; Castagnolli, 1992; Castagnolli \& Cyrino, 1986).

Para a expansão da aqüicultura brasileira e seu desenvolvimento tecnológico são necessárias, entre outros fatores, a produção de alevinos de qualidade superior e a nutrição adequada para as principais espécies, dentro dos diversos sistemas de produção adotados. Lovshin \& Cyrino (1998), analisando a situação e as perspectivas da produção comercial de pescado no Brasil, destacaram o potencial do país tornar-se um importante fornecedor mundial de pescado de água doce a partir do cultivo de espécies nativas e exóticas.

Em função dos elevados custos ligados à nutrição na piscicultura, o aproveitamento adequado dos alimentos tem grande importância no sucesso da atividade e na redução do impacto ao meio ambiente. Estudos sobre a nutrição e determinação de exigências nutricionais são, portanto, ferramentas importantes para a consolidação de uma piscicultura comercial racional e com viabilidade econômica.

Considerando-se o grande número de espécies nativas com potencial para a aqüicultura, existe a demanda por pesquisas que determinem os níveis adequados de nutrientes para essas espécies, permitindo a formulação de dietas que conduzam à produção econômica e em escala suficiente para abastecer os mercados interno e externo 
(Borghetti \& Ostrensky, 2000; Castagnolli \& Cyrino, 1986), reduzindo-se, dessa forma, a pressão de exploração sobre os estoques naturais.

As informações sobre as exigências em vitaminas para a maioria das espécies são ainda restritas e os resultados de estudos com salmonídeos, ciprinídeos, ciclídeos e outros grupos exóticos são, geralmente, aplicados comercialmente a outras espécies (De Silva \& Anderson, 1995). Em relação ao pacu, Martins (1995) e Martins et al. (1995), utilizando dietas não purificadas suplementadas com ácido ascórbico revestido de palmitato (microencapsulado), sugeriram o nível de $50 \mathrm{mg}$ de ácido ascórbico por quilograma de dieta como suficiente para o desenvolvimento normal de alevinos da espécie e $139 \mathrm{mg} \mathrm{kg}^{-1}$ como o nível ótimo sob condições de laboratório.

O objetivo deste trabalho foi observar os efeitos da inclusão de uma fonte estável de vitamina $\mathrm{C}$ em dietas semipurificadas no desenvolvimento de alevinos de pacu mantidos em sistema intensivo de produção. 


\section{REVISÃO DE LITERATURA}

\subsection{A aquiicultura e a espécie}

Embora sendo praticada há cerca de 4000 anos, a aqüicultura nunca forneceu mais do que uma fração do consumo humano de pescado (Ackefors et al., 1994), o que demonstra a dependência em relação aos estoques naturais. A produção mundial de pescado estimada para o ano de 2001 foi de 128,8 milhões de toneladas, sendo 91,3 milhões de toneladas provenientes de captura e 37,5 milhões de toneladas fornecidas pela aqüicultura $(29,1 \%$ do total) (FAO, 2002). A participação da aqüicultura na produção aqüícola mundial tem apresentado crescimento maior que qualquer outro setor da produção animal, com taxa média de 9,2\% ao ano desde 1970 até 2000. Já a captura de pescado e a produção da pecuária terrestre cresceram 1,4\% e 2,8\% ao ano, respectivamente, no mesmo período (FAO, 2002).

Observando-se os dados da FAO (1999) e Ostrensky et al. (2000), pode-se verificar a expressiva taxa de crescimento da aqüicultura brasileira nos últimos anos, quando comparada à média mundial. A produção mundial da aqüicultura cresceu $132 \%$ entre 1988 e 1997, enquanto a produção brasileira teve um aumento de 393\%, saltando de cerca de 23,4 mil toneladas em 1991 para cerca de 115,4 mil toneladas em 1998. Desse total produzido, os peixes de água doce predominam com $80 \%$, seguidos pela carcinicultura marinha com $14 \%$.

Apesar do crescimento citado, pode-se verificar que a produção da aqüicultura no Brasil é responsável por menos de $0,5 \%$ da produção mundial. Em levantamento feito 
em todo o Brasil, Ostrensky et al. (2000) relataram que a produção está concentrada na Região Sul (com quase metade do total), seguida pelas Regiões Nordeste e Sudeste.

O potencial para o desenvolvimento da aqüicultura no Brasil existe não apenas pela diversidade de espécies, mas também como consequiência da limitação de recursos pesqueiros naturais e do aumento dos custos de captura. As espécies endêmicas ou nativas de elevado potencial zootécnico são alternativas para esse desenvolvimento (Saint-Paul, 1986).

A disponibilidade de rações extrusadas no mercado impulsionou o desenvolvimento da aqüicultura intensiva de espécies tropicais no Brasil, embora existam ainda alguns problemas quanto a níveis e disponibilidade de alguns nutrientes, ao uso de ingredientes de baixa qualidade e perda de nutrientes durante o processamento e armazenamento dos produtos e às informações sobre as exigências nutricionais das espécies, considerando os sistemas de produção adotados. Os produtores têm preferência pelo uso deste tipo de ração pela facilidade de observação do consumo pelos animais, pelo melhor desempenho proporcionado e menor impacto na qualidade da água (Kubitza \& Cyrino, 1999; Kubitza et al., 1998; Pezzato, 1999).

O pacu, Piaractus mesopotamicus Holmberg 1887, uma espécie originária da bacia dos rios Paraná-Paraguai, apresenta como principais características alta capacidade de aproveitamento de ingredientes de origem vegetal na dieta, carne firme e de excelente sabor, ser um peixe reofílico (migrador) de desova total e uma espécie muito apta para a produção em confinamento. Está incluído na família Characidae, a qual engloba a maior parte dos peixes de água doce do Brasil com cerca de 400 espécies. No ambiente natural, sua maturação sexual ocorre por volta dos quatro anos de idade (cerca de $34 \mathrm{~cm}$ de comprimento total) e, do ponto de vista comercial, seu tamanho mínimo para captura é de $40 \mathrm{~cm}$ de comprimento (Britski, 1970; Ferraz de Lima, 1993).

Em experimentos de longa duração (ciclo de produção de até dois anos), verificourse a influência da temperatura sobre o desenvolvimento do pacu. A época de maior crescimento e ganho de peso coincide com as estações da primavera e verão, quando a temperatura na água é maior (acima de $24^{\circ} \mathrm{C}$ ). Temperaturas abaixo desse valor 
causam redução e até estabilização no crescimento (Cestarolli et al., 1984; Torloni et al., 1984).

A espécie possui hábito alimentar onívoro/herbívoro, o que desperta interesse para a aqüicultura, em função de sua capacidade de aproveitamento de ingredientes de origem vegetal na dieta. Fernandes et al. (2001) e Kubitza (1990) demonstraram a viabilidade da substituição parcial e total de ingredientes de origem animal (farinha de peixe) pelo farelo de soja em rações para o pacu. Além disso, características como rusticidade, rápido crescimento, fácil adaptação a rações comerciais, docilidade no manejo e aceitação pelo mercado consumidor, tornam essa espécie uma das mais produzidas no país (Brener, 1988; Carneiro, 1983; Castagnolli, 1992; Castagnolli \& Cyrino, 1986; Cestarolli et al., 1984; Torloni et al., 1984).

Em levantamento sobre as espécies mantidas em estabelecimentos para pesca esportiva no Estado de São Paulo, os peixes "redondos" - pacu, tambaqui e seus híbridos - são os que ocorrem em maior percentual nestes estabelecimentos, segundo Venturieri (2002). O pacu é uma das espécies brasileiras com maior número de trabalhos científicos publicados nas áreas de biologia, ecologia, nutrição e aqüicultura. Apesar disso, muitas dúvidas ainda existem sobre as exigências nutricionais e fisiologia dessa espécie, dada a grande diversidade de sistemas de cultivo, ambientes ocupados, ingredientes e aditivos para rações, manejo do cultivo e outros fatores que determinam diferentes respostas dos animais (Reunião do Grupo de Trabalho de Colossoma e Piaractus, 1999).

\subsection{Metabolismo e nutrição}

O metabolismo dos peixes sofre influência de vários fatores, tanto ambientais como aqueles inerentes aos próprios animais. O tamanho corporal é um deles - quanto maior o animal, menor é a quantidade de energia por unidade de peso necessária para a manutenção de seu metabolismo basal. Sendo animais pecilotérmicos, os peixes não despendem energia para a regulação térmica em seu metabolismo, o que representa uma vantagem em relação aos animais de sangue quente. A produção de calor em peixes é 
pequena e as variações de temperatura no tecido muscular, mesmo em atividade, são mínimas. Dessa forma, o metabolismo basal tem relação direta com a temperatura da água. Já o metabolismo ativo, dependendo da espécie, pode apresentar aumento com a temperatura ou atingir um nível constante e depois diminuir. A diferença entre o metabolismo basal e o ativo reflete o consumo de oxigênio disponível para a atividade do animal. A osmorregulação, a incidência de fatores estressores, o estado fisiológico e o nível de atividade motora também influenciam o metabolismo dos animais (De Silva \& Anderson, 1995; Hepher, 1988; Steffens, 1989).

Para que o crescimento, reprodução e outras funções fisiológicas dos peixes ocorram normalmente, é necessário que as exigências nutricionais sejam adequadamente supridas, considerando-se as diferenças entre as espécies cultivadas. Os alimentos encontrados pelos peixes na natureza e em condições extensivas de cultivo têm alta qualidade, apresentando composição nutricional próxima às exigências das espécies e, portanto, devem ser considerados na nutrição sob essas condições (De Silva, 1994; Hepher, 1988; Tacon, 1994). Já em condições de criação em regime intensivo, onde o alimento natural é restrito, todos os nutrientes essenciais devem ser obtidos do alimento fornecido, o qual deve conter ingredientes altamente digestíveis e em proporções que permitam seu máximo aproveitamento (De Silva \& Anderson, 1995; Fracalossi, 1998; Lovell, 1991; Lovell, 1998; Tacon, 1992).

A qualidade da alimentação está relacionada ao quanto os nutrientes fornecidos suprem as exigências dos animais. Além da correta proporção entre os nutrientes, eles devem ter digestibilidade e absorção em níveis que permitam seu aproveitamento no metabolismo dos peixes, ou seja, devem apresentar alta biodisponibilidade (De Silva \& Anderson, 1995; Lovell, 1998).

Entre os nutrientes exigidos, proteínas e lipídeos contribuem para a produção de energia em peixes, assim como nos animais terrestres. Porém, nos peixes, a exigência protéica é quantitativamente maior que a energética, como consequiência de um menor dispêndio de energia para locomoção, excreção nitrogenada e incremento calórico e de uma maior capacidade de utilização de energia a partir do catabolismo de proteínas em relação aos carboidratos, os quais têm aproveitamento diferenciado de acordo com o 
hábito alimentar da espécie, sendo pequeno para os peixes carnívoros e maior para os onívoros (Lovell, 1991; National Research Council - NRC, 1983; NRC, 1993; Tacon, 1990).

Para um crescimento adequado, as dietas para peixes e crustáceos devem conter entre 24 e $57 \%$ de proteína, correspondendo a 30 a $70 \%$ da energia bruta da dieta sob a forma de proteína, que deve apresentar adequado balanço e disponibilidade de aminoácidos e uma adequada relação energia:proteína (Lovell, 1991; Steffens, 1989; Tacon, 1990; Wilson, 1985; Wilson, 1998). Quantidades de proteínas inadequadas na dieta causam uma redução ou mesmo a parada no crescimento em peixes. Em dietas deficientes, proteína corporal de tecidos menos vitais é degradada para a manutenção de tecidos vitais e, quando em excesso, somente parte da proteína ingerida é utilizada na biossíntese de proteínas corporais, sendo o restante utilizado como fonte de energia, implicando em gasto de energia para a excreção de resíduos nitrogenados (Wilson, 1989).

A necessidade de proteína na dieta é influenciada por fatores como tamanho corporal, temperatura da água, presença de alimento natural no ambiente de criação, densidade de estocagem, taxa de alimentação diária, teor de energia não-protéica na dieta e qualidade da proteína fornecida (NRC, 1983). Em trabalhos sobre exigência nutricional para o pacu, os níveis ótimos de proteína bruta $(\mathrm{PB})$ geralmente estão entre 26\% e 37\% (Brener, 1988; Carneiro, 1983; Castagnolli et al., 1994; Fernandes et al., 2001; Kubitza, 1990). Em formulações propostas para Colossoma macropomum (tambaqui) e pacu, Bernardino \& Lima (1999) sugerem valores médios de 35 a $42 \%$ de PB para reprodutores, 25 a 32\% de PB para crescimento em viveiros e $32 \%$ de PB para crescimento em gaiolas.

Os peixes alimentam-se para suprir suas exigências em energia, tornando a energia dietética um ponto de regulação do consumo de alimento. Quantidades adequadas são necessárias para uma produção econômica, mas o excesso de energia leva ao acúmulo de gordura e redução da qualidade da carcaça (De Silva \& Anderson, 1995).

Os ácidos graxos livres, derivados dos triglicerídeos da dieta, são a principal fonte de energia para o metabolismo muscular aeróbio em peixes. Eles têm maior 
importância como fonte energética em peixes de clima temperado, pois estes têm menor capacidade de utilização dos carboidratos da dieta (Wilson, 1998). Os lipídeos são fontes de ácidos graxos essenciais, além de serem componentes das membranas celulares, precursores de hormônios e atuarem como transportadores na absorção de vitaminas lipossolúveis, entre outras funções. Alguns tipos de ácidos graxos são essenciais e devem ser obrigatoriamente fornecidos, como os ácidos graxos poliinsaturados da série $\omega 3$, em quantidades de 0,5 a $1,5 \%$ da dieta. O óleo de soja apresenta em sua composição até cerca de $8 \%$ de ácido linolênico $(\omega 3)$ e $50 \%$ de ácido linolêico ( $\omega 6$ ) (De Silva \& Anderson, 1995; Steffens, 1989; Tacon, 1990).

Peixes onívoros têm boa capacidade de utilização de energia consumida sob a forma de carboidratos, que são formas mais econômicas de energia e permitem um efeito "economizador" de proteína, a qual ficaria destinada ao crescimento. A habilidade de adaptação do peixe a dietas com alto teor de carboidratos pode ser dependente de sua capacidade de converter o excesso de energia em lipídeos ou aminoácidos não-essenciais (Tacon, 1990). Não há exigência em carboidratos definida para peixes, sendo fornecidos para reduzir custos e substituir os lipídeos e proteínas na produção de energia, em níveis que variam de 20 a 50\%, dependendo da espécie considerada (Wilson, 1998). Em estudo com diferentes níveis de carboidratos em dietas de tambacu (híbrido entre tambaqui e pacu), Carneiro et al. (1994) determinaram o nível de $45 \%$ de carboidratos como o mais adequado, em dietas com $3900 \mathrm{kcal}$ de energia bruta por quilograma.

Os minerais são exigidos pelos animais para a manutenção de suas funções metabólicas e para o crescimento normal. Uma peculiaridade existente é o fato de alguns deles, como o cálcio, serem obtidos diretamente da água. Apesar dessa capacidade e da presença de minerais nos ingredientes normalmente usados nas rações, as dietas práticas devem ser suplementadas com minerais com o objetivo de prevenir deficiências e maximizar o crescimento (Lovell, 1991; NRC, 1983; NRC, 1993; Steffens, 1989, Tacon, 1990; Tacon, 1992; Wilson, 1998).

Vitaminas são compostos essenciais ao crescimento e metabolismo, normalmente não sintetizadas em quantidades suficientes pelos animais, sendo geralmente exigidas em pequenas quantidades a partir da dieta para a manutenção da 
função fisiológica normal. Essas exigências variam, como nos outros nutrientes citados, em função de características metabólicas e ambientais e, apesar das quantidades exigidas serem pequenas, as deficiências podem causar sérios efeitos sobre os animais (Combs Jr., 1998; Halver, 1985; Lovell, 1998; NRC, 1993; Tacon, 1990).

\subsection{Vitaminas}

Vitaminas são compostos orgânicos distintos de aminoácidos, carboidratos e lipídeos por não serem quimicamente relacionados entre si e pelas pequenas quantidades presentes nos alimentos e exigidas pelos animais. Têm baixo peso molecular e não são sintetizadas ou são sintetizadas em quantidades insuficientes no organismo, sendo, portanto, exigidas na dieta. Apresentam funções específicas no metabolismo celular, atuando como cofatores ou substratos em algumas reações metabólicas e, ao contrário dos outros tipos de nutrientes, não desempenham função estrutural e seu catabolismo não tem função de produção de energia. Além disso, sua carência causa síndromes de deficiência específicas (Combs Jr., 1998; De Silva \& Anderson, 1995; Lovell, 1998; NRC, 1993; Steffens, 1989; Tacon, 1990).

O termo vitamina geralmente é aplicado como descrição genérica para um grupo de substâncias químicas relacionadas e com mesma atividade biológica, pois poucas delas são substâncias únicas. Apresentam derivados, isômeros e análogos com atividade vitamínica qualitativamente semelhante, porém com potencial biológico geralmente diferente (Combs Jr., 1998; Halver, 1989; Steffens, 1989).

Cerca de 15 vitaminas foram isoladas de tecidos biológicos, sendo classificadas em dois grupos: lipossolúveis - A, D, E e K - e hidrossolúveis (vitaminas do complexo B, colina , inositol e ácido ascórbico). Geralmente as do primeiro grupo não atuam como coenzimas, com exceção das vitaminas A e K. Entre as vitaminas hidrossolúveis, algumas têm função primária de coenzimas no metabolismo celular (tiamina, riboflavina, piridoxina, ácido pantotênico, niacina, biotina, ácido fólico e cianocobalamina) e são exigidas em pequenas quantidades; outras não atuam como cofatores de enzimas (colina, inositol e ácido ascórbico) e são exigidas em maiores 
quantidades. As exigências em vitaminas são afetadas por fatores como espécie, tamanho corporal, taxa de crescimento, composição da dieta e interações entre os nutrientes, capacidade de síntese por microorganismos no trato gastrointestinal, presença de compostos precursores na dieta, condições ambientais (temperatura, presença de metabólitos tóxicos, fatores estressores e patógenos) e sistemas de produção (De Silva \& Anderson, 1995; Hepher, 1988; Lovell, 1991; Lovell, 1998; NRC, 1993; Steffens, 1989; Tacon, 1990; Teskeredžic et al., 1989).

As vitaminas lipossolúveis são absorvidas no trato gastrointestinal na presença de lipídeos e, caso exista um excesso na dieta, elas podem ser armazenadas no tecido adiposo, podendo chegar até níveis tóxicos - são as hipervitaminoses. Por outro lado, as vitaminas hidrossolúveis não são armazenadas no organismo em grandes quantidades, tornando importante o fornecimento constante através da dieta para que não ocorram deficiências (NRC, 1993; Halver, 1989; Tacon, 1990; Wessels \& Hopson, 1988).

Vitaminas em quantidades inadequadas na dieta podem resultar em deficiências nos animais, em vários estágios ou graus de intensidade (Combs Jr., 1998). Em mamíferos, a ausência de vitaminas geralmente causa doenças nutricionais características. Já em peixes, esses sinais são menos especificamente identificados, com apenas algumas vitaminas mostrando sinais clínicos definidos, dependendo dos processos metabólicos envolvidos (Fracalossi, 1998; Lovell, 1991; NRC, 1993).

Os sinais mais comuns de deficiência em vitaminas em peixes são relacionados a alterações morfológicas e fisiológicas geralmente pouco específicas, como a redução do apetite, menor taxa de crescimento, anemia, letargia, pigmentação anormal e maior suscetibilidade a doenças. Algumas vitaminas causam sinais de deficiência mais característicos em peixes, como consequiência das funções exercidas no organismo, como alterações na visão e epitélio (vitamina A), hemorragias (vitamina K), espasmos musculares e fraqueza (niacina) e deformidades estruturais (vitamina C) (De Silva \& Anderson, 1995; Halver, 1989; Hepher, 1988; Lovell, 1991; Lovell, 1998; NRC, 1993; Steffens, 1989).

Os efeitos biológicos dos nutrientes são geralmente estudados isoladamente, em parte pela dificuldade de trabalho com a interação entre eles. Sabe-se, porém, que os 
nutrientes atuam de forma inter-relacionada no metabolismo. Entre os fatores que afetam essa interação estão a composição da dieta, o processamento, a espécie, o estado fisiológico e fatores ambientais. Podem ocorrer interações entre duas vitaminas (efeito aditivo entre vitamina $\mathrm{C}$ e $\mathrm{E}$ na prevenção da peroxidação de lipídeos, por exemplo), entre vitaminas e minerais, e entre vitaminas e outros componentes da dieta (carboidratos, proteínas e lipídeos) (Fracalossi, 1998; Hilton, 1989).

Existem poucos trabalhos sobre exigências em vitaminas para as espécies brasileiras. A literatura sobre exigências qualitativas e quantitativas em vitaminas para peixes abrange principalmente espécies exóticas - como salmonídeos, ciprinídeos, ictalurídeos e ciclídeos. Estudos devem ainda ser realizados para a determinação dessas exigências para várias espécies, com o objetivo de melhorar o crescimento, saúde e mecanismos de defesa (Lovell, 1991, Lovell, 1998; NRC, 1993).

A inclusão de vitaminas em alimentos para peixes é uma prática necessária em regimes intensivos de produção, onde a disponibilidade de alimento natural é restrita. A dificuldade em suplementar adequadamente esses nutrientes deve-se à alta degradabilidade das moléculas de vitamina durante o processamento e armazenamento das rações, como consequiência do aquecimento, umidade e oxidação. Em consequiência dessas perdas, geralmente são utilizadas quantidades maiores que as exigidas. Portanto, o nível de suplementação, a escolha de fontes mais estáveis ao processamento e estocagem e a exigência nutricional das espécies devem ser considerados para se evitar um aumento do custo das rações (De Silva \& Anderson, 1995; Hepher, 1988; Kubitza et al., 1998; Lovell, 1991; NRC, 1993; Steffens, 1989).

\subsection{Vitamina C na nutrição de peixes}

A maioria dos animais tem a capacidade de sintetizar a vitamina $\mathrm{C}$ ou Lácido ascórbico $\left(\mathrm{C}_{6} \mathrm{H}_{8} \mathrm{O}_{6}\right)$ a partir da D-glucose $\left(\mathrm{C}_{6} \mathrm{H}_{12} \mathrm{O}_{6}\right)$. Porém, na maioria dos peixes, morcegos, humanos e alguns primatas, a enzima responsável pela catalização da última etapa dessa reação no fígado, L-gulono-1,4-lactona oxidase (GLO), não tem atividade 
(Fracalossi et al., 2001; Halver, 1989; Lovell, 1991; Lovell, 1998; Nelson \& Cox, 2000; NRC, 1993; Steffens, 1989).

Fracalossi et al. (2001) analisaram a atividade da GLO no rim e fígado de 13 espécies de peixes amazônicos, incluindo 11 teleósteos, entre os quais quatro representantes da ordem Characiformes com diferentes hábitos alimentares (um deles o tambaqui, Colossoma macropomum, espécie que produz híbridos férteis com o pacu), com o objetivo de avaliar a influência da alimentação sobre a atividade da GLO. A atividade da GLO não foi detectada nas espécies de Characiformes e nos outros teleósteos, confirmando a hipótese que peixes desse grupo não sintetizam ácido ascórbico. Ressalta-se, assim, a importância da determinação da exigência em vitamina C para a espécie escolhida neste trabalho.

Alguns grupos de peixes têm atividade da GLO no rim e, portanto, são capazes de sintetizar o ácido ascórbico, como os da Família Potamotrigonidae (raia de água doce) e da Classe Sarcopterygii (pirambóia) avaliados por Fracalossi et al. (2001), e o esturjão (Osteichthyes, Acipenseriformes) estudado por Moreau et al. (1999).

Nos peixes, o ácido ascórbico pode ser encontrado sob duas formas, uma reduzida e ativa (L-ácido ascórbico) e outra oxidada e com menor atividade (ácido dehidroascórbico). Ambas são biologicamente reversíveis e apresentam atividade vitamínica (Combs Jr., 1998; Halver, 1989; Lovell, 1998; NRC, 1993; Steffens, 1989). Se o ácido dehidroascórbico for oxidado a ácido dicetogulônico (uma reação irreversível), sua atividade de vitamina C é perdida (Lovell, 1998). Microminerais como cobre, ferro e outros catalisadores metálicos são fortes agentes oxidantes e, juntamente com o calor, causam a inativação da vitamina C (Halver, 1989; Tacon, 1992).

O ácido ascórbico da dieta é oxidado a ácido dehidroascórbico, o qual pode ser revertido a L-ácido ascórbico pela dehidroascorbato redutase, conservando assim o ascorbato nos tecidos. O ascorbato-2-sulfato é uma forma química estável de ascorbato armazenada no tecido conjuntivo dos peixes. Um mecanismo de retroalimentação mediado pelo sistema enzimático ascorbato-2-sulfohidrolase e ascorbato-2-sulfato sulfosintetase e modulado pelo L-ácido ascórbico, controla o nível de ácido ascórbico no sistema circulatório e nos tecidos (Halver, 1985). 
O ácido ascórbico atua no organismo como agente redutor no transporte de hidrogênio no interior das células. Ele está envolvido na desintoxicação de drogas aromáticas, síntese de hormônios esteróides, participa de vários sistemas enzimáticos de hidroxilação, entre os quais a transformação de prolina em hidroxiprolina (um dos componentes do colágeno e da matriz extracelular), na síntese de carnitina (metabolismo de lipídeos), na utilização do ácido fólico e no metabolismo do ferro. É necessário na formação de ossos, cartilagens e dentes, assim como na recuperação de fraturas e na cicatrização de ferimentos. Interage com a vitamina E e o selênio na manutenção da atividade das enzimas glutationa peroxidase e superóxido dismutase, importantes na eliminação de radicais oxidantes produzidos no metabolismo. No sangue, está envolvido na maturação de eritrócitos, na coagulação e na manutenção da hemoglobina em níveis normais (Combs Jr., 1998; De Silva \& Anderson, 1995; Halver, 1985; Halver, 1989; Hilton, 1989; Lovell, 1998; Navarre \& Halver, 1989; Nelson \& Cox, 2000; NRC, 1993; Steffens, 1989; Tacon, 1990; Wilson \& Poe, 1973).

As exigências em vitamina $\mathrm{C}$ dependem de fatores como o tamanho corporal, a taxa de crescimento, composição da dieta, reprodução, presença de fatores estressores físicos e/ou ambientais e presença de patógenos (Halver, 1985; NRC, 1993). Uma exigência em ácido ascórbico da ordem de $100 \mathrm{mg} \mathrm{kg}^{-1}$ de dieta pode subir para $500 \mathrm{a}$ $1000 \mathrm{mg} \mathrm{kg}^{-1}$ se os peixes estiverem sob condições severas de estresse, o que seria de cinco a dez vezes o valor exigido normalmente (Halver, 1985; Navarre \& Halver, 1989).

Li \& Lovell (1985) estudaram o efeito de megadoses de vitamina C para o bagre do canal (Ictalurus punctatus), em experimento com desafio por Edwardsiella ictaluri, causadora da septicemia entérica do bagre do canal. Nas dietas não suplementadas, a mortalidade foi de $100 \%$, enquanto nas dietas suplementadas com $3000 \mathrm{mg}$ de ácido ascórbico por quilograma foi nula. Segundo esses autores, megadoses de ácido ascórbico aumentam a produção de anticorpos e a atividade do sistema imunológico. Fracalossi (1998) revisou vários trabalhos sobre o efeito da vitamina C sobre o sistema imunológico e relatou que o aumento na resistência às infecções é causado, principalmente, pelo efeito positivo do ácido ascórbico nos sistemas nãoespecíficos de defesa, como a fagocitose e a atividade do sistema de complemento. 
Estudando os efeitos da suplementação de reprodutores com ácido ascórbico, Eskelinen (1989) encontrou um aumento na sobrevivência de ovos e larvas de salmão do atlântico nas dietas suplementadas com vitamina C. Em adição, peixes apresentam maior tolerância a agentes poluentes, pesticidas e metais pesados quando a ingestão de ácido ascórbico é alta e as reservas corporais estão elevadas (Halver, 1985). Da mesma forma, a presença desses fatores aumenta as exigências em vitamina C na dieta (Lovell, 1998; NRC, 1993).

Dados de exigências em vitamina $\mathrm{C}$ para várias espécies revelam grandes variações nos valores encontrados, como 100 a $800 \mathrm{mg} \mathrm{kg}^{-1}$ para peixes carnívoros de clima temperado (Halver, 1985), 40 a $500 \mathrm{mg} \mathrm{kg}^{-1}$ para salmonídeos (NRC, 1993; Steffens, 1989), 50 a $200 \mathrm{mg} \mathrm{kg}^{-1}$ para tilápias (Lim, 1989; NRC, 1993), 650 a 750 mg $\mathrm{kg}^{-1}$ para a carpa indiana (Mahajan \& Agrawal, 1980) e valores de 11 a $200 \mathrm{mg} \mathrm{kg}^{-1}$ para o bagre do canal (Ictalurus punctatus) (Andrews \& Murai, 1975; Lovell, 1991; NRC, 1993; Steffens, 1989;). Em relação ao pacu, Castagnolli et al. (1994), Martins (1995) e Martins et al. (1995) sugeriram o nível de $50 \mathrm{mg}$ de ácido ascórbico por quilograma de dieta como suficiente para o desenvolvimento normal da espécie e $139 \mathrm{mg} \mathrm{kg}^{-1}$ como o nível ótimo sob condições de laboratório, utilizando dietas não purificadas e ácido ascórbico revestido de palmitato (microencapsulado).

Os sinais de deficiência em vitamina $\mathrm{C}$ são vários, sendo normalmente precedidos de sinais pouco específicos como anorexia, letargia e redução no crescimento. Entre eles, podem ser citados: a natação errática e no fundo; desempenho reprodutivo reduzido; deformidades estruturais (escoliose, lordose, fusão entre vértebras, ruptura da coluna vertebral, anormalidades nas cartilagens de suporte dos olhos e brânquias, alterações nos opérculos, erosão de nadadeiras, encurtamento de lamelas branquiais e epitélio branquial mais delgado que o normal); escurecimento da pele; empalidecimento das brânquias e órgãos internos; hemorragias em órgãos internos, tecido muscular e sob a pele; opacidade de córnea; cicatrização lenta; ascite; exoftalmia hemorrágica; altos níveis de colesterol e triglicerídeos no plasma; reduzida resistência a doenças, agentes estressores e poluentes (Andrews \& Murai, 1975; Lim \& Lovell, 1978; Navarre \& Halver, 1989; NRC, 1993; Steffens, 1989; Tacon, 1992; Teskeredžic et al., 
1989; Wilson \& Poe, 1973). Os sinais clínicos clássicos de escorbuto relacionados a deformidades e hemorragias são causados basicamente pela hidroxilação deficiente da prolina e lisina na formação do colágeno (componente dos ossos, cartilagens, paredes dos vasos sangüíneos e pele) (Halver, 1985; Lovell, 1998).

Como citado anteriormente, os nutrientes não agem de forma independente no organismo, mas sim relacionados entre si. Essas interações são afetadas por fatores ligados à dieta, ao animal e ao ambiente (Hilton, 1989). Níveis baixos de triptofano na dieta elevariam a exigência em vitamina $C$ para a degradação e eliminação de aminoácidos desnecessários (Halver, 1989).

$\mathrm{O}$ ácido ascórbico interage com a vitamina $\mathrm{E}$, agindo de forma sinérgica na prevenção da oxidação de lipídeos no organismo. Sua capacidade redutora recuperaria as formas intermediárias de $\alpha$-tocoferol até seu estado inicial, criando um efeito "economizador" de vitamina E para o organismo. Como em outros animais, há uma interação entre vitamina $\mathrm{C}$ e metabolismo do ferro. Deficiência em ácido ascórbico causa redução dos níveis de ferro no plasma, redução dos níveis de hemoglobina e hematócrito e anemia. A suplementação com vitamina $\mathrm{C}$ não elevaria a absorção de ferro, mas um excesso de ferro causaria redução dos níveis de ascorbato no fígado e maior oxidação de lipídeos. Essas interações ainda precisam ser mais estudadas em peixes (Hilton, 1989).

Os ingredientes comerciais para rações praticamente não possuem ácido ascórbico (Lovell, 1998), tornando necessária a suplementação com fontes resistentes ao processamento. Substâncias conjugadas de fosfato e sulfato de ácido ascórbico são muito estáveis e resistentes à oxidação durante o preparo e armazenamento das ações (BASF, 1996; NRC, 1993; Lovell, 1998). Esses compostos desenvolvidos pela indústria química, entre os quais as formas conjugadas com fosfato (mono e polifosfato) possuem atividade vitamínica e biodisponibilidade semelhantes ao L-ácido ascórbico cristalino, sendo alternativas para a fabricação de alimentos para peixes (BASF, 1996). 


\section{MATERIAL E MÉTODOS}

O experimento foi conduzido no Laboratório de Nutrição de Peixes do Setor de Piscicultura do Departamento de Produção Animal da Escola Superior de Agricultura "Luiz de Queiroz", campus "Luiz de Queiroz" da Universidade de São Paulo,

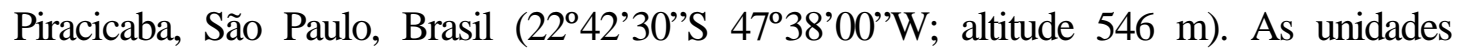
experimentais foram constituídas por lotes de alevinos de pacu alojados em gaiolas de PVC atóxico (abertura de malha de $5 \mathrm{~mm}$ ) com capacidade para $60 \mathrm{~L}$ instaladas em um tanque de alvenaria com capacidade para $12 \mathrm{~m}$, em um sistema fechado de recirculação equipado com moto-bomba (1,5 hp, vazão de $\left.12,6 \mathrm{~m}^{3} \mathrm{~h}^{-1}\right)$ e filtro de areia. A água utilizada era proveniente de poço artesiano profundo do Setor de Piscicultura e sua qualidade foi monitorada através das variáveis temperatura $\left({ }^{\circ} \mathrm{C}\right)$, oxigênio dissolvido $\left(\mathrm{OD}, \mathrm{mg} \mathrm{L}^{-1}\right)$ e $\mathrm{pH}$, com medições pela manhã e à tarde, usando-se oxímetro e medidor de $\mathrm{pH}$ eletrônicos portáteis.

Foram estocados 600 alevinos de pacu (peso inicial 9,06 $\pm 1,40 \mathrm{~g}$ ), adquiridos de produtor comercial, distribuídos nas gaiolas em lotes de 15 alevinos e adaptados às instalações por cinco dias antes do início do experimento. Nesse período, foram alimentados com uma mistura de dieta experimental (100 mg vit. $\left.\mathrm{C} \mathrm{kg}^{-1}\right)$ e ração comercial adicionada de antibiótico (cloridrato de oxitetraciclina, $60 \mathrm{mg} \mathrm{kg}^{-1}$ ).

Os ensaios foram conduzidos em delineamento experimental inteiramente casualizado, sendo cada tratamento constituído por uma das dez dietas experimentais, com quatro repetições por tratamento. Os tratamentos foram definidos como os níveis de inclusão de vitamina $\mathrm{C}$, sob a forma de monofosfato de ácido ascórbico com $42 \%$ de atividade $\quad$ Lutavit $^{\circledR} \quad \mathrm{C}$ Monophosphate, BASF), nas dietas experimentais semipurificadas. O monofosfato de ácido ascórbico na forma de sal cálcico foi escolhido 
como fonte de vitamina $\mathrm{C}$ pois, juntamente com o polifosfato de ácido ascórbico, são compostos resistentes ao calor, têm perdas reduzidas durante o processamento e apresentam maior estabilidade (menor lixiviação) na água (BASF, 1998; Gadient \& Schai, 1994; Halver, 1989; Soliman et al., 1987). Além disso, são formas de vitamina C que permitem retenção elevada deste nutriente durante a estocagem de dietas extrusadas para peixes (Gadient \& Fenster, 1994). Foram empregados dez níveis de inclusão de vitamina $C$ nas dietas: 0 (controle), 50, 100, 150, 200, 250, 300, 500, 700 e $900 \mathrm{mg}$ de vitamina $\mathrm{C}$ por quilograma da dieta (Tabela 1$)$.

Tabela 1. Composição das dietas experimentais (\%)

\begin{tabular}{|c|c|c|c|c|c|c|c|c|c|c|}
\hline Ingredientes & R1 & $\mathbf{R 2}$ & $\mathbf{R 3}$ & R4 & R5 & R6 & $\mathbf{R 7}$ & $\mathbf{R 8}$ & R9 & R10 \\
\hline Albumina & 32,100 & 32,100 & 32,100 & 32,100 & 32,100 & 32,100 & 32,100 & 32,100 & 32,100 & 32,100 \\
\hline Gelatina & 7,700 & 7,700 & 7,700 & 7,700 & 7,700 & 7,700 & 7,700 & 7,700 & 7,700 & 7,700 \\
\hline Amido & 43,980 & 43,980 & 43,980 & 43,980 & 43,980 & 43,980 & 43,980 & 43,980 & 43,980 & 43,980 \\
\hline Óleo de soja & 6,000 & 6,000 & 6,000 & 6,000 & 6,000 & 6,000 & 6,000 & 6,000 & 6,000 & 6,000 \\
\hline$\alpha$-Celulose & 6,200 & 6,188 & 6,176 & 6,164 & 6,152 & 6,140 & 6,128 & 6,080 & 6,033 & 5,985 \\
\hline Fosfato bicálcico & 3,000 & 3,000 & 3,000 & 3,000 & 3,000 & 3,000 & 3,000 & 3,000 & 3,000 & 3,000 \\
\hline Mist. vitamínico-mineral ${ }^{1}$ & 0,500 & 0,500 & 0,500 & 0,500 & 0,500 & 0,500 & 0,500 & 0,500 & 0,500 & 0,500 \\
\hline Vitamina $\mathrm{C}^{2}$ & 0,000 & 0,012 & 0,024 & 0,036 & 0,048 & 0,060 & 0,072 & 0,120 & 0,167 & 0,215 \\
\hline Cloreto de sódio & 0,500 & 0,500 & 0,500 & 0,500 & 0,500 & 0,500 & 0,500 & 0,500 & 0,500 & 0,500 \\
\hline BHT $^{3}$ & 0,020 & 0,020 & 0,020 & 0,020 & 0,020 & 0,020 & 0,020 & 0,020 & 0,020 & 0,020 \\
\hline Total & 100,00 & 100,00 & 100,00 & 100,00 & 100,00 & 100,00 & 100,00 & 100,00 & 100,00 & 100,00 \\
\hline \multicolumn{11}{|c|}{$\begin{array}{l}{ }^{1} \text { Níveis de garantia por quilograma da mistura vitamínico-mineral: vit.A } 1.200 .000 \mathrm{UI} \text {; vit.D } 200.000 \\
\text { UI; vit.E } 12.000 \mathrm{mg} \text {; vit.K } 2.400 \mathrm{mg} \text {; vit.B } 4.800 \mathrm{mg} \text {; vit.B } \mathrm{B}_{2} 4.800 \mathrm{mg} \text {; vit.B } 4.000 \mathrm{mg} \text {; vit.B } \mathrm{B}_{12} 4.800 \\
\mathrm{mg} \text {; ácido fólico } 1.200 \mathrm{mg} \text {; pantotenato de cálcio } 1.200 \mathrm{mg} \text {; biotina } 48 \mathrm{mg} \text {; niacina } 24.000 \mathrm{mg} \text {; colina } \\
500 \mathrm{mg} \text {; Fe } 10.000 \mathrm{mg} \text {; Cu } 600 \mathrm{mg} \text {; Mn } 4.000 \mathrm{mg} \text {; Zn } 6.000 \mathrm{mg} \text {; I } 20 \mathrm{mg} \text {; Co } 2 \mathrm{mg} \text {; Se } 20 \mathrm{mg} \text {. }\end{array}$} \\
\hline${ }^{2}$ Lutavit $^{\circledR} \mathrm{C}$ Monophsphate & BASF (sa & al cálcico & 2-mono & osfato de & ácido as & córbico, & $42 \%$ de 1 & rincípio & ativo) & \\
\hline
\end{tabular}


As dietas experimentais semipurificadas foram preparadas segundo as recomendações de Halver (1989) e NRC (1993), de forma similar a dietas de baixa umidade, através de peletização por compressão. Em estudos de exigência nutricional, o uso de dietas semipurificadas é essencial para que haja a simulação da deficiência em relação ao nutriente investigado (De Silva \& Anderson, 1995; Halver, 1985; Lovell, 1998; NRC, 1983; NRC, 1993; Soliman et al., 1987). Os ingredientes secos foram misturados, adicionados de óleo e homogeneizados. Em seguida, foi adicionada água para dar plasticidade à mistura, em proporção de cerca de 15 a $20 \%$ do peso dos ingredientes e a mistura resultante foi transferida para um moedor industrial especial de 2 hp equipado com controle eletrônico de torque e reversor. O material produzido foi quebrado em pedaços menores, seco em estufa a $45^{\circ} \mathrm{C}$ por 20 horas, triturado e peneirado até o tamanho médio de $3 \mathrm{~mm}$ e congelado a $-20^{\circ} \mathrm{C}$.

No período do experimento, as embalagens com as dietas foram pesadas semanalmente e mantidas em refrigerador $\left( \pm 5^{\circ} \mathrm{C}\right)$ para melhor conservação. $\mathrm{O}$ restante foi mantido à temperatura de $-20^{\circ} \mathrm{C}$. $\mathrm{O}$ controle do consumo de ração foi realizado semanalmente através de pesagem das sobras de alimento nos recipientes relativos a cada unidade experimental (gaiola). A composição nutricional calculada das dietas experimentais é apresentada na Tabela 2.

Tabela 2. Composição nutricional das dietas calculada

\begin{tabular}{lc}
\hline Nutrientes & Níveis \\
\hline Proteína Bruta (\%) & 32,40 \\
Energia Digestível $\left(\mathrm{kcal} \mathrm{kg}^{-1}\right)$ & 3107 \\
Extrato Etéreo (\%) & 6,11 \\
Carboidratos (\%) & 45,79 \\
Matéria Mineral (\%) & 5,95 \\
\hline
\end{tabular}

Relação ED/PB calculada: $\quad 9,60 \mathrm{kcal} \mathrm{g} \mathrm{PB}^{-1}$ 
Os peixes foram alimentados ad libitum em duas refeições diárias, às 8 horas e às 17 horas, sete dias por semana, por um período de nove semanas (63 dias). Diariamente e até o final do experimento foram feitas observações visuais quanto ao comportamento e sinais externos característicos de deficiência, além de ocorrência de mortalidade. Foram analisados seis índices de desempenho zootécnico: peso final (PF, g), ganho de peso (GDP, g), consumo de ração (CR, g), conversão alimentar (CA) e taxa de crescimento específico (TCE, \% dia ${ }^{-1}$ ), sendo:

$$
\begin{array}{ll}
\text { GDP }(\mathrm{g})=\text { PF-PI } & \text { PI }=\text { peso inicial } \\
\text { CA }=\text { CR } \div \text { GDP } & \\
\text { TCE }=100 \times[(\ln \text { PF }-\ln \text { PI }) \div \text { Per }] & \text { Per = período experimental (dias) }
\end{array}
$$

Os parâmetros de desempenho avaliados neste experimento seguiram as descrições e recomendações de De Silva \& Anderson (1995), Erfanullah \& Jafri (1999), Moore et al. (1988), Steffens (1989) e Tacon (1990).. e a coleta dos dados de desempenho foi realizada ao final do período experimental. Para a pesagem dos animais foi utilizada como anestésico a benzocaína, na dosagem de $50 \mathrm{mg} \mathrm{L}^{-1}$.

Ao final do período experimental foram selecionados quatro peixes por tratamento, referentes a cada uma das repetições, para coleta de sangue para a análise dos seguintes parâmetros hematológicos: contagem de eritrócitos $\left(\mathrm{GV}, 10^{6} \mu \mathrm{L}^{-1}\right)$, hematócrito (HCT, \%), volume corpuscular médio $\left(\mathrm{VCM}, \mu \mathrm{m}^{3}\right)$, hemoglobina $(\mathrm{Hb}, \mathrm{g}$ $\mathrm{dL}^{-1}$ ) e contagem de leucócitos totais ( $\mathrm{GB}$, células $\left.\mu \mathrm{L}^{-1}\right)$. Após anestesia com benzocaína, o sangue foi coletado por punção da veia caudal e conservado em gelo. Para a coleta foram utilizadas seringas contendo solução de EDTA $10 \%\left(50 \mu \mathrm{L} \mathrm{mL}^{-1}\right)$ como anticoagulante. As análises de GV, HCT, VCM e $\mathrm{Hb}$ foram realizadas em contador eletrônico de células $\left(\right.$ CELM $^{\circledR}$ modelo CC550) e a GB foi realizada em câmara de Neubauer espelhada, utilizando-se o corante Natt-Herrick em diluição de 200:1 (corante:sangue) (Natt \& Herrick, 1952).

Foram feitos exames radiológicos para a análise de eventuais deformidades ósseas existentes nos animais, selecionando-se o maior e o menor peixe de cada 
tratamento, dentre todas as repetições, totalizando 20 animais. Os exames foram realizados em equipamento radiológico General Electric ${ }^{\circledR}$ modelo 1000, utilizando-se filmes de base verde $\operatorname{Kodak}^{\circledR}$ MXG/Plus, em chassi radiológico $\operatorname{Kodak}^{\circledR}(18 \times 24 \mathrm{~cm})$, com placa intensificadora de médio contraste, equipado com divisor de filmes. Foram feitas duas radiografias por peixe em cada filme - uma lateral e outra ventral -, com distância focal de $60 \mathrm{~cm}$. Para a posição lateral, o equipamento foi calibrado em $15 \mathrm{~mA}$, 4 impulsos e $45 \mathrm{KVp}$ (peixes maiores) e $15 \mathrm{~mA}, 3$ impulsos e $45 \mathrm{KVp}$ (peixes menores). Para a posição ventral, a calibração foi de $10 \mathrm{~mA}, 6$ impulsos e $55 \mathrm{KVp}$ (peixes maiores) e $10 \mathrm{~mA}, 5$ impulsos e $50 \mathrm{KVp}$ (para os menores).

Os dados obtidos foram submetidos à análise de variância usando-se o software SAS (SAS, 2000), adotando-se, quando necessário, o método de transformação por potência ótima de Box-Cox $(\alpha=0,05)$. O efeito linear ou quadrático dos níveis de suplementação com vitamina $\mathrm{C}$ sobre as variáveis peso inicial $(\mathrm{PI})$, peso final $(\mathrm{PF})$, ganho de peso (GDP), consumo de ração (CR), conversão alimentar (CA), taxa de crescimento específico (TCE), contagem de eritrócitos (GV), hematócrito (HCT), volume corpuscular médio (VCM), hemoglobina ( $\mathrm{Hb})$ e contagem de leucócitos totais (GB) foi analisado através de regressão polinomial, segundo as recomendações de Snedecor \& Cochran (1989) e Steel \& Torrie (1960). Para a determinação de valores ótimos da suplementação com vitamina $\mathrm{C}$ foi utilizada a regressão não-linear segmentada, aplicada às variáveis através do procedimento PROC NLIN do SAS, de acordo com as recomendações de Portz et al. (2000) e Zeitoun et al. (1976). 


\section{RESULTADOS E DISCUSSÃO}

\subsection{Qualidade da água}

Durante o período experimental, os parâmetros de qualidade da água monitorados mantiveram-se dentro dos limites adequados para espécies tropicais e os valores encontrados são semelhantes aos de outros experimentos com o pacu. Carneiro (1983) encontrou valores de temperatura variando de 28 a $32^{\circ} \mathrm{C}$ como os mais adequados para a espécie. Torloni et al. (1984) afirmaram que, em temperaturas entre 26,7 e $28,8^{\circ} \mathrm{C}$, há melhor desenvolvimento dos peixes com maiores incrementos em ganho de peso e comprimento total, em tanques de $1000 \mathrm{~m}^{2}$. Em condições de laboratório, Fernandes et al. (2001) obtiveram valores médios de temperatura entre 27,89 e $28,51^{\circ} \mathrm{C}, \mathrm{pH}$ entre 6,8 e 7,6 e oxigênio dissolvido médio de $4,84 \mathrm{mg} \mathrm{L}^{-1}$ durante período experimental de 100 dias.

Os valores de oxigênio dissolvido encontrados foram adequados e não restringiram o crescimento, ficando próximos dos valores recomendados por Boyd (1990) para ambiente tropical e acima dos valores mínimos de 3,0 a 4,0 $\mathrm{mg} \mathrm{L}^{-1}$ e 5,0 mg $\mathrm{L}^{-1}$, citados por Colt \& Montgomery (1991) e Castagnolli (2000), respectivamente. Os valores de $\mathrm{pH}$ também ficaram dentro dos limites de 6,5 a 9,0 recomendados por Boyd (1990). As médias das variáveis monitoradas estão apresentadas na Tabela 3. 
Tabela 3. Médias dos parâmetros de qualidade da água durante o experimento

\begin{tabular}{lccccc} 
Parâmetro & $\mathbf{n}^{1}$ & Mínimo & Máximo & Média & C.V. $(\%)^{2}$ \\
\hline Temperatura $(8 \mathrm{~h})\left({ }^{\circ} \mathrm{C}\right)$ & 63 & 24,8 & 28,0 & $26,64 \pm 0,796$ & 2,99 \\
$\mathrm{pH}(9 \mathrm{~h})$ & 9 & 7,72 & 8,30 & $7,93 \pm 0,234$ & 2,95 \\
$\mathrm{OD}^{3}(9 \mathrm{~h})\left(\mathrm{mg} \mathrm{L}^{-1}\right)$ & 14 & 6,10 & 7,72 & $6,78 \pm 0,586$ & 8,65 \\
Temperatura $(17 \mathrm{~h})\left({ }^{\circ} \mathrm{C}\right)$ & 63 & 25,7 & 30,4 & $28,23 \pm 1,183$ & 4,19 \\
$\mathrm{pH}(17 \mathrm{~h})$ & 13 & 7,78 & 8,38 & $8,06 \pm 0,199$ & 2,47 \\
OD $(17 \mathrm{~h})\left(\mathrm{mg} \mathrm{L}^{-1}\right)$ & 16 & 6,05 & 7,01 & $6,66 \pm 0,267$ & 4,02 \\
\hline${ }^{1}$ Número de observações & & & & & \\
2 Coeficiente de variação & & & & &
\end{tabular}

\subsection{Desempenho}

A análise de variância das variáveis de desempenho não detectou diferença significativa entre as médias dos tratamentos $(\mathrm{P}>0,05)$. As médias de peso inicial (PI), peso final (PF), ganho de peso (GDP), consumo de ração (CR), conversão alimentar (CA) e taxa de crescimento específico (TCE) estão na Tabela 4. Os valores de PI não diferiram significativamente entre os tratamentos $(\mathrm{P}>0,05)$, demonstrando a homogeneidade de peso nas parcelas no início do experimento. As médias de PF dos tratamentos não diferiram entre si $(\mathrm{P}>0,05)$, mas as análises de regressão mostraram uma tendência linear de aumento do PF com maiores doses de vitamina C na dieta (Figura 1). Segundo a análise de regressão não-linear segmentada, adotando-se o modelo de uma reta, o nível ótimo estimado para essa variável seria de 423,1 mg de vitamina $\mathrm{C} \mathrm{kg}^{-1}$ $(\mathrm{P}=0,053)$. 
Tabela 4. Médias das variáveis de desempenho analisadas para os tratamentos*

\begin{tabular}{lcccccc}
$\begin{array}{l}\text { Variáveis de } \\
\text { desempenho }\end{array}$ & PI & PF & GDP & CR & CA & TCE \\
\hline Tratamentos & g & g & g & g & \% dia $\mathbf{~}^{-1}$ \\
T1 $(0 \mathrm{mg})$ & $120,93 \pm 24,98$ & $733,65 \pm 19,61$ & $612,72 \pm 12,97$ & $589,48 \pm 10,91$ & $0,963 \pm 0,03$ & $2,89 \pm 0,29$ \\
T2 (50 mg) & $137,63 \pm 16,88$ & $719,10 \pm 45,52$ & $581,47 \pm 29,59$ & $567,94 \pm 25,24$ & $0,977 \pm 0,02$ & $2,63 \pm 0,11$ \\
T3 (100 mg) & $129,12 \pm 29,34$ & $742,37 \pm 45,36$ & $613,26 \pm 24,04$ & $581,11 \pm 12,60$ & $0,949 \pm 0,03$ & $2,81 \pm 0,28$ \\
T4 (150 mg) & $135,70 \pm 15,05$ & $738,44 \pm 27,38$ & $602,74 \pm 13,61$ & $570,92 \pm 10,62$ & $0,947 \pm 0,01$ & $2,70 \pm 0,12$ \\
T5 (200 mg) & $138,78 \pm 15,94$ & $739,53 \pm 34,85$ & $600,75 \pm 20,70$ & $577,48 \pm 29,47$ & $0,961 \pm 0,03$ & $2,66 \pm 0,12$ \\
T6 (250 mg) & $151,35 \pm 38,56$ & $736,84 \pm 77,79$ & $585,49 \pm 43,41$ & $569,77 \pm 15,33$ & $0,976 \pm 0,05$ & $2,55 \pm 0,29$ \\
T7 (300 mg) & $135,93 \pm 12,57$ & $753,00 \pm 32,10$ & $617,08 \pm 37,30$ & $572,36 \pm 10,76$ & $0,929 \pm 0,04$ & $2,72 \pm 0,18$ \\
T8 (500 mg) & $136,03 \pm 4,64$ & $746,55 \pm 35,23$ & $610,53 \pm 31,36$ & $568,34 \pm 13,22$ & $0,932 \pm 0,03$ & $2,70 \pm 0,04$ \\
T9 (700 mg) & $133,30 \pm 16,31$ & $771,38 \pm 11,51$ & $638,08 \pm 19,06$ & $578,56 \pm 8,98$ & $0,907 \pm 0,02$ & $2,79 \pm 0,19$ \\
T10 (900 mg) & $131,00 \pm 24,12$ & $747,83 \pm 6,39$ & $616,83 \pm 25,05$ & $579,40 \pm 9,06$ & $0,941 \pm 0,04$ & $2,79 \pm 0,29$ \\
\hline
\end{tabular}

PI: Peso inicial; PF: Peso final; GDP: Ganho de peso; CR: Consumo de ração; CA: Conversão alimentar; TCE: Taxa de crescimento específico

* Médias das parcelas $(\mathrm{n}=4) \pm$ desvio padrão

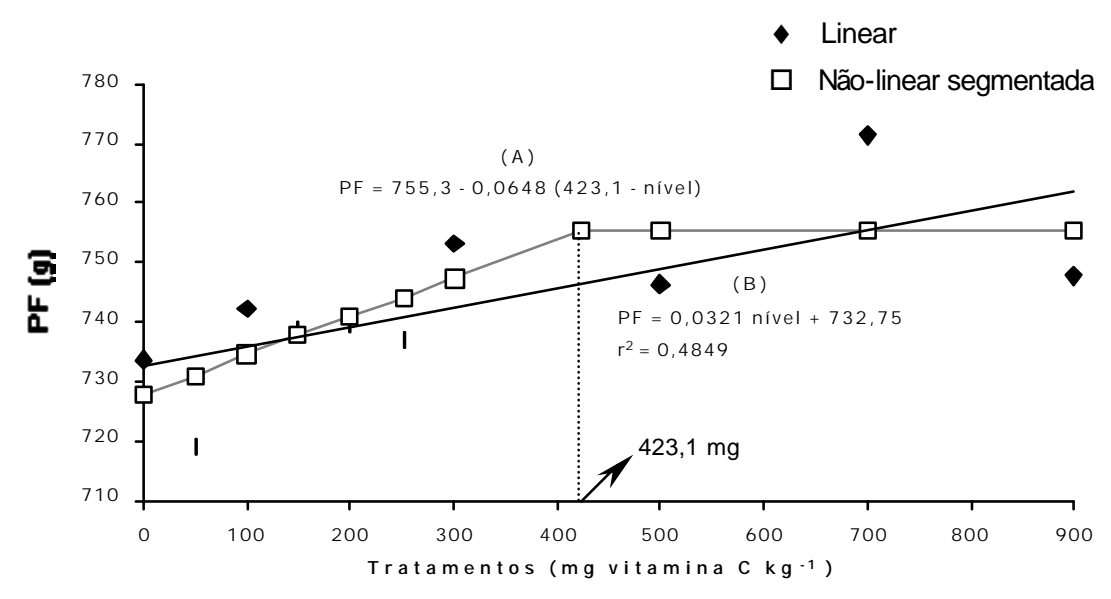

Figura 1 - Regressões para as médias de peso final (PF), em função do nível de vitamina $\mathrm{C}$ na dieta: (A) não-linear segmentada, (B) linear 
As médias de GDP dos tratamentos apresentaram apenas tendência linear positiva em função de maiores doses de vitamina $\mathrm{C}$ na dieta $(\mathrm{P}>0,05)$, não sendo possível determinar um nível ótimo pela regressão não-linear segmentada, conforme apresentado na Figura 2. O diferencial médio de peso entre o início e o final do período experimental, expresso como $[100 \times(\mathrm{PF}-\mathrm{PI}) / \mathrm{PI}$, foi de 460,8\% para os tratamentos, demonstrando uma boa adaptação dos peixes às dietas, instalações e ao manejo nesse período. O ganho de peso médio por peixe foi de 40,81 $\mathrm{g}\left(0,65 \mathrm{~g} \mathrm{dia}^{-1}\right)$.

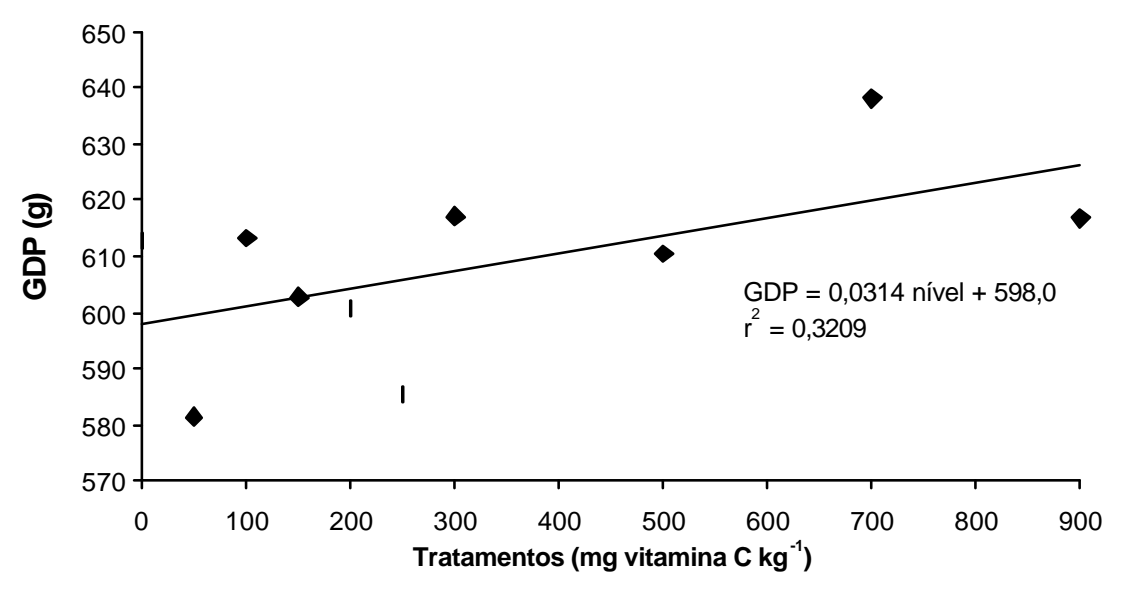

Figura 2 - Regressão polinomial para as médias de ganho de peso (GDP) dos peixes em resposta aos diferentes níveis de vitamina $\mathrm{C}$ na dieta

O consumo de ração (CR) das parcelas não diferiu significativamente entre os tratamentos $(\mathrm{P}>0,05)$ durante o período experimental. $\mathrm{O}$ consumo diário médio de ração durante os 63 dias de alimentação foi de $0,61 \mathrm{~g}$ por peixe e a perda de alimento foi praticamente nula. As médias de conversão alimentar (CA) dos tratamentos não foram diferentes entre si $(\mathrm{P}>0,05)$, mas houve efeito linear negativo significativo das doses crescentes de vitamina $\mathrm{C}$ nas dietas sobre as médias de $\mathrm{CA}(\mathrm{P}=0,038)$. Através da análise de regressão não-linear segmentada com o modelo de uma reta, foi determinado o valor de $635,7 \mathrm{mg}$ de vitamina $\mathrm{C}$ por quilograma de dieta no ponto de quebra ( $\mathrm{P}=0,068)$ para essa variável (Figura 3 ). 
Os excelentes valores de CA encontrados durante o trabalho foram resultado da perda praticamente nula de alimento, em consequiência do fornecimento lento e bem distribuído das rações aos peixes, nas duas refeições fornecidas diariamente. Merola \& Souza (1988) obtiveram valores de CA de 2,85 a 3,25 para o pacu (50 a $200 \mathrm{~g}$ de peso), fornecendo ração peletizada (30\% PB), em gaiolas de 0,5 $\mathrm{m}^{3}$. Castagnolli et al. (1994), em trabalho sobre a suplementação com vitamina $C$ para o pacu, obtiveram valores de CA aparente próximos a 68 , com ração experimental (30\% PB) e peixes com peso inicial de $8,64 \pm 1,62 \mathrm{~g}$, durante 24 semanas.

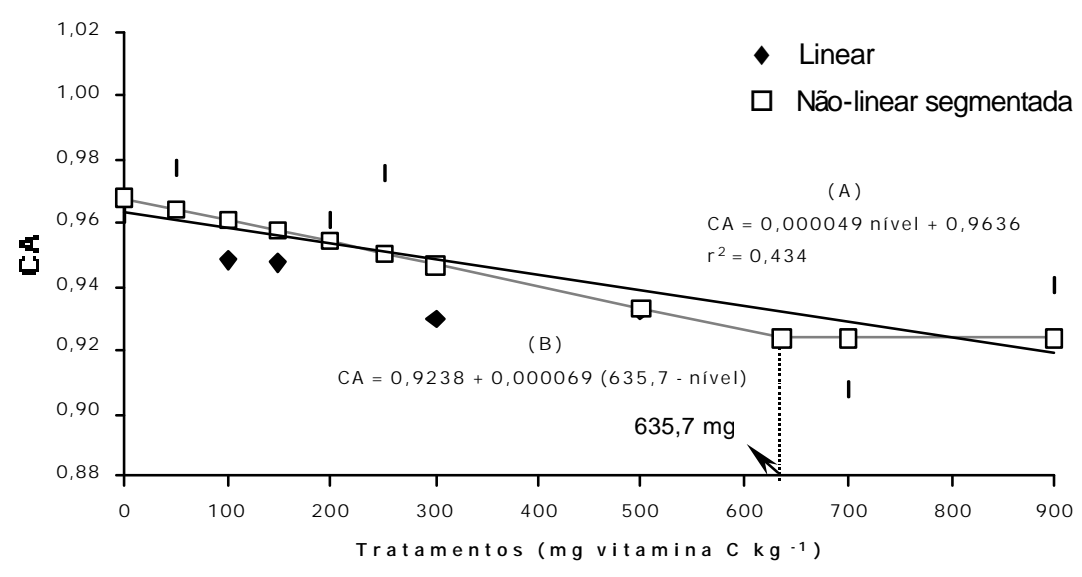

Figura 3 - Regressões para as médias de conversão alimentar (CA), em função do nível de vitamina $\mathrm{C}$ na dieta: (A) linear, (B) não-linear segmentada

As médias da taxa de crescimento específico (TCE) não diferiram entre os tratamentos $(\mathrm{P}>0,05)$. Os valores encontrados foram elevados, todos acima de $2,5 \% \mathrm{dia}^{-1}$ (média de $2,72 \% \mathrm{dia}^{-1}$ ), demonstrando novamente que os peixes apresentaram alta taxa de crescimento durante o período. Lee et al. (1998) obtiveram valores de 0,44 a 1,08\% dia $^{-1}$ para a TCE em estudo sobre suplementação com vitamina C em dietas semipurificadas para o "Korean rockfish" (Sebastes schlegeli Hilgendorf). Henrique et al. (1998) conseguiram valores médios de $1,74 \% \mathrm{dia}^{-1}$ para a TCE, trabalhando com dietas experimentais $(45 \%$ PB) à base de farinha de peixe para o seabream (Sparus aurata) com peso inicial de cerca de sete gramas. Erfanullah \& Jafri (1999) encontraram 
valores de TCE de 1,27 a 2,25\% dia $^{-1}$ e de 1,51 a 2,76 para a CA trabalhando com dietas semipurificadas por 8 semanas para o Heteropneustes fossilis Bloch. Fernandes et al. (2001) encontraram valores de TCE entre 0,31 e 0,36 \% para juvenis de pacu (peso inicial variando entre 80 e 144 g), mantidos em condições de laboratório por 100 dias.

\subsection{Hematologia}

Não foi detectada diferença entre as médias dos tratamentos $(\mathrm{P}>0,05)$. As médias de contagem de eritrócitos (GV), hematócrito (HCT), volume corpuscular médio (VCM), hemoglobina ( $\mathrm{Hb})$ e contagem de leucócitos totais (GB) estão na Tabela 5. Para a análise de variância das médias de GV, HCT e GB para os tratamentos, foi necessária a transformação dos dados pelo método de potência ótima de Box-Cox, sendo usado o inverso das médias de GV e HCT e o $\log _{10}$ GB para a aplicação do teste F.

As médias de $\mathrm{GV}$ dos tratamentos apresentaram efeito linear negativo na regressão em função de maiores doses de vitamina $\mathrm{C}$ na dieta $(\mathrm{P}<0,05)$, mas não foi possível determinar o ponto de quebra na regressão não-linear segmentada, conforme apresentado na Figura 4. O valor médio de $2,03 \times 10^{6} \mu \mathrm{L}^{-1}$ encontrado para a GV neste trabalho foi superior à média de $1,71 \times 10^{6} \mu \mathrm{L}^{-1}$ encontrada por Tavares Dias et al. (1999) em estudo hematológico sobre pacus coletados em pesque-pagues (policultivo intensivo). Esse valor também foi superior à média de $1,68 \times 10^{6} \mu \mathrm{L}^{-1}$ determinada por Tocidlowski et al. (1997) para a pirapitinga (Colossoma brachypomum), mas situa-se dentro do intervalo de $1,15 \times 10^{6} \mu \mathrm{L}^{-1}$ a $2,94 \times 10^{6} \mu \mathrm{L}^{-1}$ encontrado por esses autores. A $\mathrm{GV}$ foi correlacionada positivamente à hemoglobina $(\mathrm{Hb})$ e negativamente ao volume corpuscular médio (VCM) nas análises deste trabalho, repetindo as correlações encontradas para esses parâmetros por Tavares Dias et al. (1999) para pacus em criação intensiva. 
Tabela 5. Médias dos parâmetros hematológicos analisados para os tratament os*

\begin{tabular}{|c|c|c|c|c|c|}
\hline $\begin{array}{c}\text { Parâmetros } \\
\text { hematológicos }\end{array}$ & GV & HCT & VCM & $\mathbf{H b}$ & GB \\
\hline Tratamentos & $10^{6} \mu \mathrm{L}^{-1}$ & $\%$ & $\mu \mathrm{m}^{3}$ & $\mathrm{~g} \mathrm{dL}^{-1}$ & células $\mu \mathrm{L}^{-1}$ \\
\hline T1 (0 mg) & $2,13 \pm 0,14$ & $28,60 \pm 1,44$ & $134,55 \pm 3,39$ & $11,08 \pm 0,49$ & $10500 \pm 1291$ \\
\hline T2 (50 mg) & $2,14 \pm 0,25$ & $28,23 \pm 2,36$ & $132,38 \pm 8,02$ & $10,85 \pm 0,65$ & $15250 \pm 10079$ \\
\hline T3 (100 mg) & $1,98 \pm 0,06$ & $27,50 \pm 0,00$ & $142,90 \pm 8,58$ & $10,85 \pm 0,62$ & $9500 \pm 4655$ \\
\hline T4 (150 mg) & $2,04 \pm 0,10$ & $28,43 \pm 1,14$ & $137,03 \pm 11,36$ & $11,63 \pm 0,67$ & $16000 \pm 5716$ \\
\hline T5 (200 mg) & $2,09 \pm 0,19$ & $30,40 \pm 2,58$ & $145,53 \pm 2,98$ & $11,30 \pm 1,01$ & $10000 \pm 1826$ \\
\hline T6 (250 mg) & $2,14 \pm 0,27$ & $29,65 \pm 2,13$ & $139,30 \pm 8,02$ & $11,45 \pm 1,26$ & $14750 \pm 7805$ \\
\hline T7 (300 mg) & $1,95 \pm 0,13$ & $28,30 \pm 2,81$ & $145,35 \pm 11,80$ & $10,53 \pm 0,87$ & $16500 \pm 2082$ \\
\hline T8 (500 mg) & $2,04 \pm 0,10$ & $29,23 \pm 2,57$ & $143,15 \pm 8,18$ & $10,28 \pm 1,19$ & $16250 \pm 6850$ \\
\hline T9 (700 mg) & $2,08 \pm 0,06$ & $29,23 \pm 1,35$ & $140,53 \pm 5,96$ & $11,23 \pm 0,41$ & $10250 \pm 5252$ \\
\hline T10 (900 mg) & $1,77 \pm 0,29$ & $24,68 \pm 2,78$ & $140,58 \pm 7,97$ & $9,95 \pm 1,19$ & $13250 \pm 9106$ \\
\hline
\end{tabular}

GV: contagem de eritrócitos; HCT: hematócrito; VCM: volume corpuscular médio; Hb: hemoglobina;

GB: contagem de leucócitos totais

* Médias das parcelas $(\mathrm{n}=4) \pm$ desvio padrão

Lim et al. (2000) encontraram aumento significativo da GV com a suplementação com vitamina $\mathrm{C}$ entre doses de 0,50 e $3000 \mathrm{mg} \mathrm{kg}^{-1}$ para o bagre do canal (Ictalurus punctatus), em dietas com diferentes níveis de ferro (0 a $\left.300 \mathrm{mg} \mathrm{kg}^{-1}\right)$. Esse efeito foi mais significativo para dietas não suplementadas com ferro. $\mathrm{O}$ aumento da GV na interação da vitamina $\mathrm{C}$ com o ferro suplementar poderia ser explicado pelo efeito do ácido ascórbico na eritropoiese. O valor médio de $2,03 \times 10^{6} \mu \mathrm{L}^{-1}$ encontrado para a GV no presente trabalho foi mais próximo aos valores máximos determinados por Lim et al. (2000) com a dose de $3000 \mathrm{mg} \mathrm{kg}^{-1}\left(2,17 \times 10^{6} \mu \mathrm{L}^{-1}\right)$ do que com as menores doses de vitamina $\mathrm{C}$ (cerca de $1,71 \times 10^{6} \mu \mathrm{L}^{-1}$ ). $\mathrm{O}$ nível de ferro das dietas utilizadas neste trabalho (50 $\mathrm{mg} \mathrm{kg}^{-1}$ ) foi adequado e não interferiu nos resultados da contagem de eritrócitos (GV). 


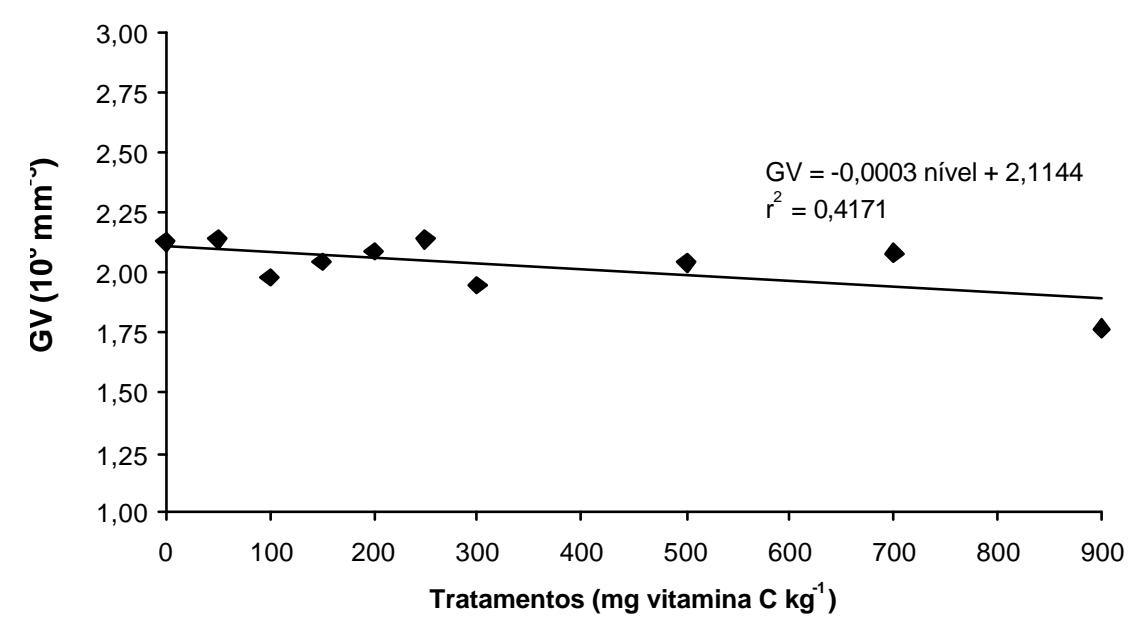

Figura 4 - Regressão polinomial para as médias de contagem de eritrócitos (GV) dos peixes em resposta aos diferentes níveis de vitamina $\mathrm{C}$ na dieta

As médias dos valores de hematócrito (HCT) para os tratamentos não diferiram entre si $(\mathrm{P}>0,05)$. $\mathrm{Na}$ análise de regressão polinomial foi encontrado efeito quadrático $(\mathrm{P}=0,024)$ dos diferentes níveis de vitamina $\mathrm{C}$ na dieta sobre os valores de HCT (Figura 5). Através da análise de regressão não-linear segmentada ajustada para o modelo de duas retas, o ponto de quebra estimado para essa variável corresponde a uma suplementação com vitamina $\mathrm{C}$ de $254,0 \mathrm{mg} \mathrm{kg}^{-1}$ de dieta.

O valor médio de 28,42\% encontrado para o HCT neste trabalho foi menor que a média de 32,5 \% encontrada por Tavares Dias et al. (1999) para o pacu, mas foi superior à média de 25,8 \% determinada por Tocidlowski et al. (1997) para a pirapitinga, situando-se dentro do intervalo de 22,0 a 32,0 \% encontrado por esses autores. O HCT foi negativamente correlacionado ao volume corpuscular médio (VCM) nas análises deste trabalho, repetindo a correlação encontrada entre esses parâmetros por Tavares Dias et al. (1999) para a espécie. Lee et al. (1998) e Lim et al. (2000) não encontraram diferenças $(\mathrm{P}>0,05)$ entre os diferentes níveis de suplementação com vitamina $\mathrm{C}$ e os valores de hematócrito, em seus estudos com alevinos de Sebastes schlegeli e Ictalurus punctatus, respectivamente. 


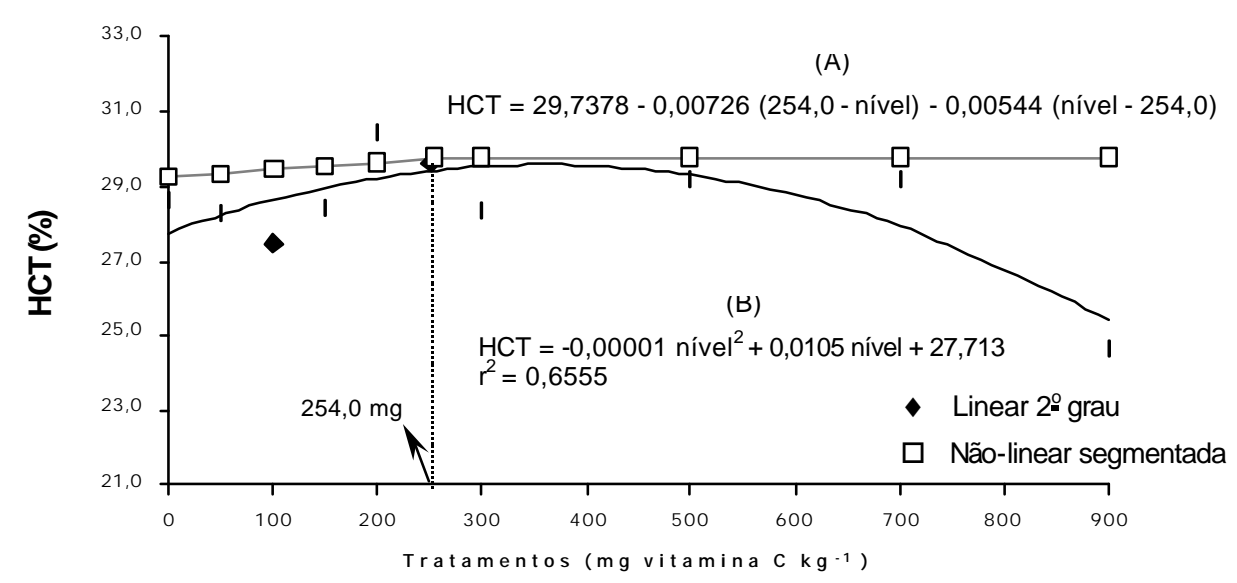

Figura 5 - Regressões para as médias de hematócrito (HCT), em resposta aos níveis de vitamina $\mathrm{C}$ na dieta: (A) não-linear segmentada, (B) quadrática

Os valores encontrados para o volume corpuscular médio (VCM) não diferiram $(\mathrm{P}>0,05)$ e existiu uma fraca evidência linear para os dados de VCM na análise de regressão não-linear segmentada $(\mathrm{P}=0,090)$, com um valor estimado em 109,7 mg de vitamina $\mathrm{C}$ por quilograma de dieta no ponto de quebra, adotando-se o modelo de uma reta (Figura 6). O valor médio de 140,13 $\mu \mathrm{m}^{3}$ encontrado foi menor que a média de 209,8 $\mu \mathrm{m}^{3}$ encontrada por Tavares Dias et al. (1999) para pacus de maior tamanho.

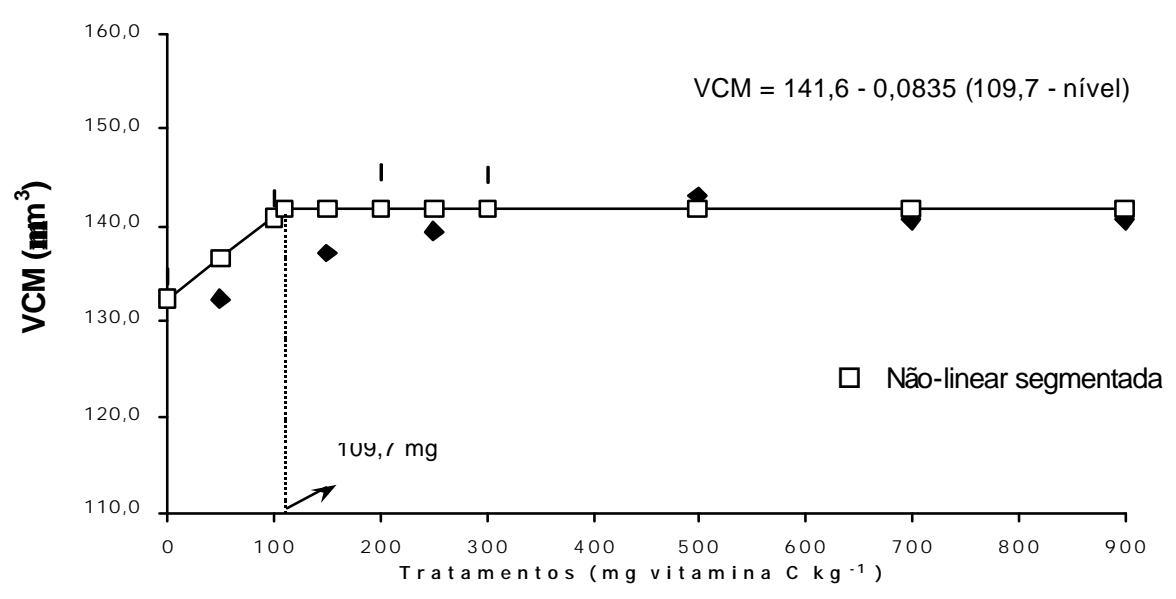

Figura 6 - Regressão não-linear segmentada para as médias de volume corpuscular médio (VCM), em resposta aos níveis de vitamina $\mathrm{C}$ na dieta 
As médias dos valores de hemoglobina $(\mathrm{Hb})$ não diferiram entre os tratamentos ( $\mathrm{P}>0,05)$. $\mathrm{O}$ valor médio de 10,91 $\mathrm{g} \mathrm{dL}^{-1}$ foi superior ao encontrado por Tavares Dias et al. (1999) para o pacu (6,6 $\left.\mathrm{g} \mathrm{dL}^{-1}\right)$, mas próximo aos encontrados por Lee et al. (1998) para alevinos de "Korean rockfish" (Sebastes schlegeli) (8,91 a 10,9 g dL ${ }^{-1}$ ). Existiu correlação positiva entre $\mathrm{Hb}$ e GV neste trabalho, coincidindo com as observações sobre a hematologia do pacu feitas por Tavares Dias et al. (1999).

Houve uma fraca evidência linear na análise de regressão polinomial de grau 1 para as médias de $\mathrm{Hb}$ dos tratamentos $(\mathrm{P}=0,103)$, com efeito negativo do aumento das doses de vitamina $\mathrm{C}$ na dieta dos peixes (Figura 7). Lim et al. (2000) observaram redução de $\mathrm{HCT}$ e $\mathrm{Hb}$ com a suplementação com vitamina $\mathrm{C}$ em dietas carentes em ferro para o bagre do canal. Quando o nível de ferro das dietas era normal, os níveis de $\mathrm{Hb}$ e o HCT não foram afetados pela suplementação com ácido ascórbico. Fica assim confirmado que a suplementação com ferro nas dietas foi adequada e não interferiu nos parâmetros hematológicos avaliados.

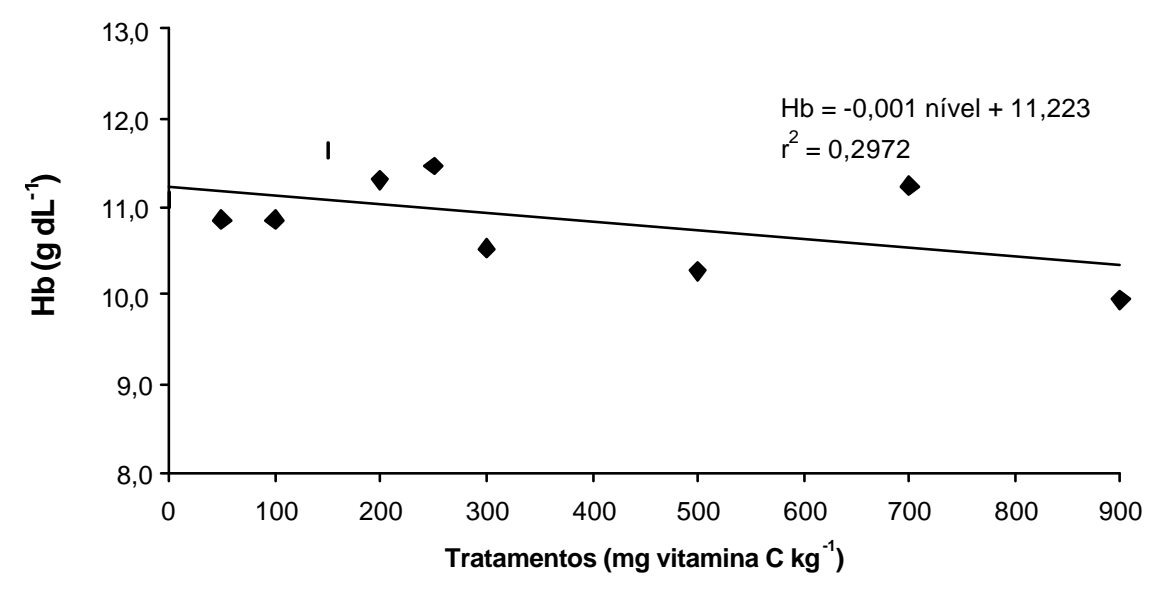

Figura 7 - Regressão polinomial para as médias de hemoglobina $(\mathrm{Hb})$ em resposta aos níveis de vitamina $\mathrm{C}$ na dieta

As médias dos valores encontrados para a contagem de leucócitos totais (GB) não diferiram entre si $(\mathrm{P}>0,05)$, mas existiu uma grande variação dos dados entre e dentro dos tratamentos. Foram encontrados valores médios nos tratamentos entre 9500 e 
16250 células $\mu \mathrm{L}^{-1}$ e, nas parcelas, a amplitude foi de 5000 a 27000 células $\mu \mathrm{L}^{-1}$, com valor médio global de 13225 células $\mu \mathrm{L}^{-1}$.

A média encontrada no presente trabalho foi inferior ao valor de 33500 células $\mu \mathrm{L}^{-1}$ (13600 a 52300) encontrado por Tocidlowski et al. (1997), em estudo hematológico com a pirapitinga (Colossoma brachypomum). Li \& Lovell (1985), avaliando o fornecimento de diferentes doses de vitamina C (0 até $\left.3000 \mathrm{mg} \mathrm{kg}^{-1}\right)$ para o bagre do canal, encontraram um aumento da produção de anticorpos e da atividade do sistema imunológico e queda da mortalidade com a megadose de $3000 \mathrm{mg} \mathrm{kg}^{-1}$.

\subsection{Radiologia}

Os exames radiológicos realizados não detectaram deformidades estruturais entre os peixes escolhidos - os maiores e os menores de cada tratamento, com exceção do menor alevino do tratamento 5. Na Figura 8, podem ser observadas as radiografias de um alevino normal de pacu, com ausência de deformidades estruturais na coluna vertebral (lordose, escoliose ou anquiloses), costelas, ossos do crânio, mandíbula, maxila e opérculos.

No alevino pequeno, referente ao tratamento 5 (suplementação com $200 \mathrm{mg}$ de vitamina C por quilograma de dieta), foi possível observar a incidência de anquilose (calcificação entre duas estruturas ósseas) entre duas vértebras da região torácica, causando uma alteração no arqueamento costal dessa região facilmente visível no exame radiológico (Figura 9). A deformidade observada neste animal pode ter sido consequiência de um menor consumo da ração, em função das relações de dominância entre os indivíduos do mesmo lote.

Navarre \& Halver (1989), em estudo com trutas arco-íris suplementadas com ácido ascórbico (0, 100, 500, 1000 e $\left.2000 \mathrm{mg} \mathrm{AA} \mathrm{kg}^{-1}\right)$, encontraram alterações ósseas (lordose e escoliose) apenas em animais recebendo a dieta não-suplementada com AA, após 18 semanas de alimentação. Mahajan \& Agrawal (1980) encontraram alterações morfológicas e ósseas em carpa indiana (Cirrhina mrigala) alimentadas com a dieta sem 
AA e nos níveis mais baixos de suplementação, de forma mais intensa, somente após cerca de 15 semanas de experimento. Foram observados peixes com escoliose, lordose, vértebras condensadas e, em alguns casos, ruptura de coluna vertebral. Lee et al. (1998) observaram alterações aparentes semelhantes em juvenis de Korean rockfish (Sebastes schlegeli) a partir de 12 semanas. Castagnolli et al. (1994) também não encontraram anormalidades esqueléticas em pacus sob diferentes níveis de suplementação com vitamina $\mathrm{C}$ após 24 semanas, demonstrando o baixo valor de exigência em vitamina $\mathrm{C}$ da espécie. 

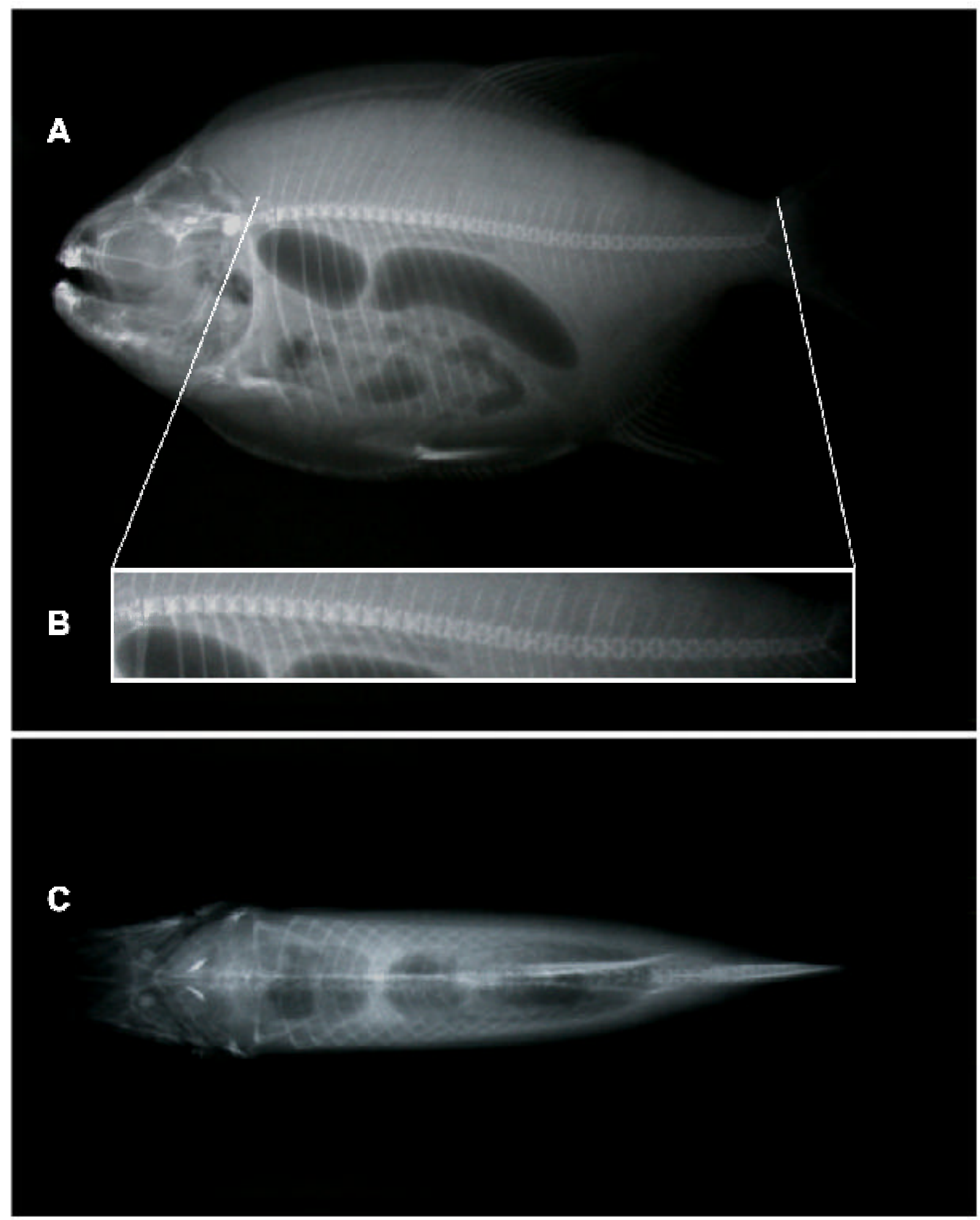

Figura 8 - Radiografias de alevino de pacu: $\boldsymbol{\Lambda}$. Posiçăo lateral; B. Detalhe da coluna vertebral (ampliado em 40\%); C. Posipio venlral 
$\mathbf{A}$

$\mathbf{B}$

$\mathbf{C}$

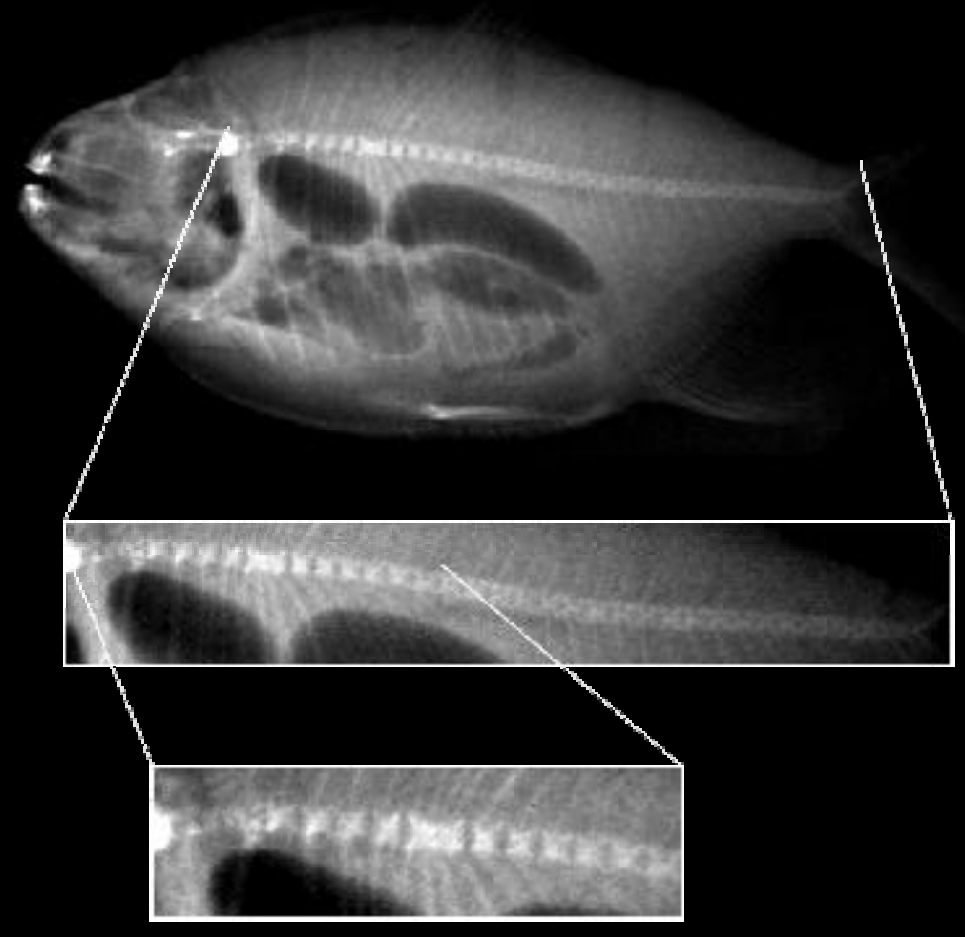

$\mathbf{D}$

lïgura 9 - Radiografias de alevino de pacu com incideneia de anquilose entre wártebras torácicas: A. Posiçio lateral; B. Detalhe da coluna vertebral (ampliado em 40\%): C. Detalhe mostrando a anquilose na regiāo torácica (ampliaçâo de 100\%); $\mathbf{D}$. Posiçaio ventral 


\section{CONCLUSÕES}

As dietas artificiais semipurificadas utilizadas permitiram alto desempenho e foram bem aceitas pelos peixes, sem a necessidade de uso de aditivos e o monofosfato de ácido ascórbico na forma de sal cálcico foi uma fonte adequada de vitamina $\mathrm{C}$ para as dietas, resistente ao processamento e armazenamento. A ausência de diferenças significativas no desempenho e de sinais aparentes de deficiência de vitamina $\mathrm{C}$ nos peixes pode indicar que as reservas corporais iniciais foram importantes na manutenção das funções fisiológicas normais durante o período avaliado. $O$ nível de ferro suplementar nas dietas $\left(50 \mathrm{mg} \mathrm{kg}^{-1}\right.$ ) foi adequado e não interferiu nos parâmetros hematológicos estudados.

A análise de regressão não-linear para peso final (PF), conversão alimentar (CA) e hematócrito (HCT) estimou os valores de 423,1, 635,7 e 254,0 mg de vitamina C por quilograma de dieta no ponto de quebra, respectivamente. Nível mínimo de 254,0 mg de vitamina $\mathrm{C}$ por quilograma de dieta, sob a forma de monofosfato de ácido ascórbico, na condição experimental estudada, foi suficiente para manter a sanidade e permitir desempenho adequado para o pacu com peso inicial de cerca de nove gramas. 


\section{REFERÊNCIAS BIBLIOGR ÁFICAS}

ACKEFORS, H.; HUNER, J.V.; KONIKOFF, M. Introduction to the general principles of aquaculture. New York: Food Products Press; The Haworth Press, 1994. 172p.

ANDREWS, J.W.; MURAI, T. Studies on the vitamin C requirements of channel catfish (Ictalurus punctatus). The Journal of Nutrition, v.105, p.557-561, 1975.

BASF. Bioavailabilities of $\mathbf{L}$-ascorbyl-2-monophosphate calcium salt and $\mathbf{L}$ ascorbyl-polyphosphate relative to crystalline Lascorbic acid in adult rainbow trout. Ludwigshafen, 1996. 5p. (Info-Service Animal Nutrition, 44/96).

BASF. Informaciones técnicas . ed. 1997/1998. Ludwigshafen, 1998. 140p.

BERNARDINO, G.; LIMA, R.V. Situação da criação de Colossoma e Piaractus no sudeste do Brasil. In: REUNIÃO DO GRUPO DE TRABALHO DE COLOSSOMA E PIARACTUS, 2., Pirassununga, 1991. Criação de Colossoma e Piaractus no Brasil. Brasília: IBAMA, 1999. p. 173-233.

BORGHETTI, J.R.; OSTRENSKY, A. A cadeia produtiva da aqüicultura brasileira. In: VALENTI, W.C. (Ed.). Aquiicultura no Brasil: bases para um desenvolvimento sustentável. Brasília: CNPq; Ministério da Ciência e Tecnologia, 2000. p. 73-106.

BOYD, C.E. Water quality in ponds for aquaculture. Birmingham: Auburn University, 1990. 482p.

BRENER, M. Determinação da exigência protéica do pacu (Colossoma mitrei Berg, 1895). Viçosa, 1988. 87p. Dissertação (Mestrado) - Universidade Federal de Viçosa. 
BRITSKI, H.A. Peixes de água doce do Estado de São Paulo - Sistemática. In: BRANCO, S.M. (Ed.). Poluição e piscicultura. São Paulo: Comissão Interestadual da Bacia Paraná-Uruguai; USP, Faculdade de Saúde Pública; Instituto de Pesca de São Paulo, 1970. p. 79-108.

CARNEIRO, D.J. Níveis de proteína e energia na alimentação do pacu (Colossoma mitrei Berg, 1895). Jaboticabal, 1983. 56p. Dissertação (Mestrado) - Faculdade de Ciências Agrárias e Veterinárias de Jaboticabal, Universidade Estadual Paulista.

CARNEIRO, D.J.; FRAGNITO, P.S.; MALHEIROS, E.B. Influence of carbohydrate and energy level on growth and body composition of tambacu, a hybrid of tambaqui (Colossoma macropomum) and pacu (Piaractus mesopotamicus). Aquaculture, v.124, n.1/4, p. 129-130, 1994.

CAStagnOLli, N. Criação de peixes de água doce. Jaboticabal: FUNEP, 1992. $189 \mathrm{p}$.

CASTAGNOLLI, N. Piscicultura intensiva e sustentável. In: VALENTI, W.C. (Ed.). Aquiicultura no Brasil: bases para um desenvolvimento sustentável. Brasília: CNPq; Ministério da Ciência e Tecnologia, 2000. p. 181-195.

CASTAGNOLli, N.; CYRINO, J.E.P. Piscicultura nos trópicos. São Paulo: Manole, 1986. $152 \mathrm{p}$.

CASTAGNOLLI, N.; MARTINS, M.L.; KRONKA, S.N. Efeitos da suplementação de vitamina C na nutrição do pacu Piaractus mesopotamicus (Holmberg, 1887). In: SIMPÓSIO BRASILEIRO DE AQÜICULTURA, 8., Piracicaba, 1994. Anais. Piracicaba: FEALQ, 1994. p. 239-251.

CESTAROLLI, M.A.; GODINHO, H.M.; VERANI, J.R.; BASILE-MARTINS, M.A.; FENERICH-VERANI, N.; LEITE, R.G. Observações sobre o comportamento do pacu, Colossoma mitrei (Berg, 1895), em tanque experimental. In: SIMPÓSIO BRASILEIRO DE AQÜICULTURA, 3., São Carlos, 1984. Anais. São Carlos: ABRAq; Universidade Federal de São Carlos, 1984. p. 537-545.

COLT, J.; MONTGOMERY, J.M. Aquacultural production systems. Journal of Animal Science, v.69, n.5, p. 4183-4192, 1991. 
COMBS JR., G.F. The vitamins: fundamental aspects in nutrition and health. New York: Academic Press, 1998. 618p.

DE SILVA, S.S. Supplementary feeding in semi-intensive aquaculture systems. In: NEW, M.B.; TACON, A.G.J.; CSAVAS, I. (Ed.). Farm-made aquafeeds. Rome: FAO, 1994. p. 24-60. (FAO Fisheries Technical Paper, 343)

DE SILVA, S.S.; ANDERSON, T.A. Fish nutrition in aquaculture. London: Chapman \& Hall, 1995. 319p.

ERFANULLAH; JAFRI, A.K. Growth, feed conversion, body composition and nutrient retention efficiencies in fingerling catfish, Heteropneustes fossilis (Bloch), fed different sources of carbohydrate. Aquaculture Research, v.30, n.1, p.43-49, 1999.

ESKELINEN, P. Effects of different diets on egg production and egg quality of Atlantic salmon (Salmo salar L.). Aquaculture, v.79, p. 275-281, 1989.

FAO. El estado mundial de la pesca y la acuicultura: 1998. Rome, 1999. 112p.

FAO. El estado mundial de la pesca y la acuicultura: 2002. Rome, 2002. 150p.

FERNANDES, J.B.K.; CARNEIRO, D.J.; SAKOMURA, N.K. Fontes e níveis de proteína bruta em dietas para juvenis de pacu (Piaractus mesopotamicus). Revista Brasileira de Zootecnia, v.30, n.3, p. 617-626, 2001.

FERRAZ DE LIMA, J.A. Recursos pesqueiros em ambientes inundáveis (Rio Cuiabá Pantanal de Mato Grosso). In: ENCONTRO BRASILEIRO DE ICTIOLOGIA, 10, São Paulo, 1993. Anais. São Paulo: Sociedade Brasileira de Ictiologia; USP, Instituto Oceanográfico, 1993. p. 302-310.

FRACALOSSI, D.M. Doenças nutricionais em peixes. In: SIMPÓSIO SOBRE MANEJO E NUTRIÇÃO DE PEIXES, 2., Piracicaba, 1998. Anais. Campinas: Colégio Brasileiro de Nutrição Animal, 1998. p. 97-122.

FRACALOSSI, D.M.; ALLEN, M.E.; YUYAMA, L.K.; OFTEDAL, O.T. Ascorbic acid biosynthesis in Amazonian fishes. Aquaculture, v.192, n.2/4, p. 321-332, 2001.

GADIENT, M.; FENSTER, R. Stability of ascorbic acid and other vitamins in extruded fish feeds. Aquaculture, v.124, p. 207-211, 1994. 
GADIENT, M; SCHAI, E. Leaching of various vitamins from shrimp feed. Aquaculture, v.124, p. 201-205, 1994.

HALVER, J.E. Recent advances in vitamin nutrition and metabolism in fish. In: COWEY, C.B.; MACKIE, A.M.; BELL, J.G. (Ed.). Nutrition and feeding in fish. London: Academic Press, 1985. p. 415-429.

HALVER, J.E. The vitamins. In: HALVER, J.E. (Ed.). Fish nutrition. 2.ed. Washington: Academic Press, 1989. p. 31-109.

HENRIQUE, M.M.F.; GOMES, E.F.; GOUILLOU COUSTANS, M.F.; OLIVA TELES, A.; DAVIES, S.J. Influence of supplementation of practical diets with vitamin $\mathrm{C}$ on growth and response to hypoxic stress of seabream, Sparus aurata. Aquaculture, v.161, n.1-4, p. 415-426, 1998.

HEPHER, B. Nutrition of pond fishes. Cambridge: Cambridge University Press, 1988. 388p.

HILTON, J.W. The interaction of vitamins, minerals and diet composition in the diet of fish. Aquaculture, v.79, p. 223-244, 1989.

KUBITZA, F. Substituição total da farinha de peixe pelo farelo de soja em rações para alevinos de pacu (Piaractus mesopotamicus Holmberg, 1887), suplementadas com metionina. Piracicaba, 1990. 80p. Dissertação (Mestrado) - Escola Superior de Agricultura “Luiz de Queiroz”, Universidade de São Paulo.

KUBITZA, F.; CYRINO, J.E.P. The effects of feed quality and feeding practices on the quality of fish: a Brazilian fish culture outlook. In: CHANG, Y.K.; WANG, S.S. (Ed.). Advances in extrusion technology: aquaculture/animal feeds and foods. Lancaster: Technomic Publ., 1999. p.53-71.

KUBITZA, F.; CYRINO, J.E.P.; ONO, E.A. Rações comerciais para peixes no Brasil: situação atual e perspectivas. Panorama da Aquiicultura, v.8, n.50, p. 38-49, 1998.

LEE, K.J.; KIM, K.W.; BAI, S.C. Effects of different dietary levels of L-ascorbic acid on growth and tissue vitamin $\mathrm{C}$ concentration in juvenile Korean rockfish, Sebastes schlegeli (Hilgendorf). Aquaculture Research, v.29, n.4, p. 237-244, 1998. 
LI, Y.; LOVELL, R.T. Elevated levels of dietary ascorbic acid increase immune responses in channel catfish. The Journal of Nutrition, v.115, p. 123-131, 1985.

LIM, C. Practical feeding - tilapias. In: LOVELL, R.T. (Ed.). Nutrition and feeding of fish. New York: Van Nostrand Reinhold, 1989. p. 163-183.

LIM, C.; LOVELL, R.T. Pathology of the vitamin C deficiency syndrome in channel catfish (Ictalurus punctatus). The Journal of Nutrition v.108, p. 1137-1146, 1978.

LIM, C.; KLESIUS, P.H.; LI, M.H.; ROBINSON, E.H. Interaction between dietary levels of iron and vitamin $\mathrm{C}$ on growth, hematology, immune response and resistance of channel catfish (Ictalurus punctatus) to Edwardsiella ictaluri challenge. Aquaculture, v.185, n.3-4, p. 313-327, 2000.

LOVELL, R.T. Nutrition of aquaculture species. Journal of Animal Science, v.69, n.5, p. 4193-4200, 1991.

LOVELL, R.T. Nutrition and feeding of fish 2.ed. Boston: Kluwer Academic, 1998. $267 \mathrm{p}$.

LOVSHIN, L.L.; CYRINO, J.E.P. Status of commercial fresh water fish culture in Brazil. In: SIMPÓSIO SOBRE MANEJO E NUTRIÇÃO DE PEIXES, 2., Piracicaba, 1998. Anais. Campinas: Colégio Brasileiro de Nutrição Animal, 1998. p. $1-20$.

MAHAJAN, C.L.; AGRAWAL, N.K. Nutritional requirement of ascorbic acid by Indian major carp, Cirrhina mrigala, during early growth. Aquaculture, v.19, p.37-48, 1980.

MARTINS, M.L. Effect of ascorbic acid deficiency on the growth, gill filament lesions and behavior of pacu fry (Piaractus mesopotamicus Holmberg, 1887). Brazilian Journal of Medical and Biological Research v.28, n.5, p. 563-568, 1995.

MARTINS, M.L.; CASTAGNOLLI, N.; ZUIM, S.M.F.; URBINATI, E.C. Influência de diferentes níveis de vitamina $\mathrm{C}$ na ração sobre parâmetros hematológicos de alevinos de Piaractus mesopotamicus Holmberg, 1887 (Osteichthyes: Characidae). Revista Brasileira de Zoologia, v.12, n.3, p. 609-618, 1995. 
MEROLA, N.; SOUZA, J.H. Preliminary studies on the culture of the pacu, Colossoma mitrei, in floating cages: effect of stocking density and feeding rate on growth performance. Aquaculture, v.68, n.3, p. 243-248, 1988.

MOORE, B.J.; HUNG, S.S.O.; MEDRANO, J.F. Protein requirement of hatcheryproduced juvenile white sturgeon (Acipenser transmontanus). Aquaculture, v.71, n.3, p. 235-245, 1988.

MOREAU, R.; DABROWSKI, K.; SATO, P.H. Renal Lgulono-1-4-lactone oxidase activity as affected by dietary ascorbic acid in lake sturgeon (Acipenser fulvescens). Aquaculture, v.180, n.3/4, p. 359-372, 1999.

NATIONAL RESEARCH COUNCIL. Nutrient requirements of warmwater fishes and shellfishes. Washington: National Academic Press, 1983. 102p.

NATIONAL RESEARCH COUNCIL. Nutrient requirements of fish Washington: National Academic Press, 1993. 114p.

NATT, M.P.; HERRICK, C.A. A new blood diluent for counting the erytrocytes and leucocytes of the chicken. Poultry Science, v.3, p. 735-738, 1952.

NAVARRE, O.; HALVER. J.E. Disease resistance and humoral antibody production in rainbow trout fed high levels of vitamin C. Aquaculture, v.79, p. 207-221, 1989.

NELSON, D.L.; COX, M.M. Lehninger principles of biochemistry. 3.ed. New York: Worth Publ., 2000. 1152p.

OSTRENSKY, A.; BORGHETTI, J.R.; PEDINI, M. Situação atual da aqüicultura brasileira e mundial. In: VALENTI, W.C. (Ed.) Aqüicultura no Brasil: bases para um desenvolvimento sustentável. Brasília: CNPq; Ministério da Ciência e Tecnologia, 2000. p. 353-381.

PEZZATO, L.E. The use of extruded feed in fish food. In: CHANG, Y.K.; WANG, S.S. (Ed.) Advances in extrusion technology: aquaculture/animal feeds and foods. Lancaster: Technomic Publ., 1999. p.35-42.

PORTZ, L.; DIAS, C.T.S.; CYRINO, J.E.P. Regressão segmentada como modelo na determinação de exigências nutricionais de peixes. Scientia Agricola, v.57, n.4, p.601-607, out./dez. 2000. 
REUNIÃO DO GRUPO DE TRABALHO DE COLOSSOMA E PIARACTUS, 2., Pirassununga, 1991. Criação de Colossoma e Piaractus no Brasil. Brasília: IBAMA, 1999. 286p.

SAINT-PAUL, U. Potential for aquaculture of South American freshwater fishes: a review. Aquaculture, v.54, p. 205-240, 1986.

SAS INSTITUTE. SAS/STAT: user's guide, statistics version 8. Cary, 2000. 3884p.

SNEDECOR, G.W.; COCHRAN, W.S. Statistical methods. 8.ed. Ames: The Iowa State University Press, 1989. 503p.

SOLIMAN, A.K.; JANUNCEY, K.; ROBERTS, J. Stability of L-ascorbic acid (vitamin C) and its forms in fish feeds during processing. Aquaculture, v.60, n.1, p. 73-83, 1987.

STEEL, R.G.D.; TORRIE, J.H. Principles and procedures of statistics. New York: McGraw-Hill, 1960. 481p.

STEFFENS, W. Principles of fish nutrition. Chichester: Ellis Horwood, 1989. 384p.

TACON, A.G.J. The essential nutrients. In: TACON, A.G.J. Standard methods for the nutrition and feeding of farmed fish and shrimp. Redmond: Argent Laboratories Press, 1990. v.1, p. 1-117.

TACON, A.G.J. Nutritional fish pathology: morphological signs of nutrient deficiency and toxicity in farmed fish. Rome: FAO, 1992. 75p. (FAO Fisheries Technical Paper, 330).

TACON, A.G.J. Feed formulation and on-farm feed management. In NEW, M.B.; TACON, A.G.J.; CSAVAS, I. (Ed.). Farm-made aquafeeds. Rome: FAO, 1994. p. 61-74. (FAO Fisheries Technical Paper, 343).

TAVARES DIAS, M.; TENANI, R.A.; GIOLI, L.D.; FAUSTINO, C.D. Características hematológicas de teleósteos brasileiros. II. Parâmetros sangüíneos do Piaractus mesopotamicus Holmberg (Osteichthyes, Characidae) em policultivo intensivo. Revista Brasileira de Zoologia, v.16, n.2, p. 423-431, 1999.

TESKEREDŽIC, Z.; TESKEREDŽIC, E.; HACMANJEK, M. High mortality of rainbow trout (Salmo gairdneri) fry caused by deficiency of vitamins $\mathrm{C}$ and $\mathrm{B}_{2}$ in commercial fish farms in Yugoslavia. Aquaculture, v.79, p. 245-248, 1989. 
TOCIDLOWSKI, M.E.; LEWBART, G.A.; STOSKOPF, M.K. Hematologic study of red pacu (Colossoma brachypomum). Veterinary Clinical Pathology, v.26, n.3, p.119-125, 1997.

TORLONI, C.E.C.; SILVA FILHO, J.A.; VERANI, J.R.; PEREIRA, J.A. Estudos experimentais sobre o cultivo intensivo do pacu, Colossoma mitrei, no Sudeste do Brasil. In: SIMPÓSIO BRASILEIRO DE AQÜICULTURA, 3., São Carlos, 1984. Anais. São Carlos: ABRAq; Universidade Federal de São Carlos, 1984. p. 559576.

VENTURIERI, R. Pesque-pague no Estado de São Paulo. São Paulo: Eco Associação para Estudos do Ambiente, 2002. 151p.

WESSELS, N.K.; HOPSON, J.L. Biology. New York: Random House, 1988. 1251p.

WILSON, R.P. Amino acid and protein requirements of fish. In: COWEY, C.B.; MACKIE, A.M.; BELL, J.G. (Ed.). Nutrition and feeding in fish London: Academic Press, 1985. p. 1-16.

WILSON, R.P. Amino acids and proteins. In: HALVER, J.E. (Ed.). Fish nutrition. 2.ed. Washington: Academic Press, 1989. p. 111-151.

WILSON, R.P. State of art of warmwater fish nutrition. In: SIMPÓSIO BRASILEIRO DE AQÜICULTURA, 10., Recife, 1998. Anais. Recife: ABRAq; ABCC; LACWAS, 1998. p.375-380

WILSON, R.P.; POE, W.E. Impaired collagen formation in the scorbutic channel catfish. The Journal of Nutrition, v.103, p. 1359-1364, 1973.

ZEITOUN, I.H.; ULLREY, D.E.; MAGEE, W.T.; GILL, J.L.; BERGEN, W.G. Quantifying nutrient requirements of fish. Journal of the Fisheries Research Board of Canada, v.33, p. 167-172, 1976. 
APÊNDICE 
Tabela 1. Médias dos parâmetros de desempenho - valores médios por gaiola

\begin{tabular}{|c|c|c|c|c|c|c|c|}
\hline \multicolumn{2}{|c|}{$\begin{array}{c}\text { Parâmetros de } \\
\text { desempenho }\end{array}$} & \multirow{2}{*}{$\begin{array}{l}\text { PI } \\
\mathrm{g}\end{array}$} & \multirow{2}{*}{$\begin{array}{c}\text { PF } \\
\mathrm{g}\end{array}$} & \multirow{2}{*}{$\begin{array}{c}\text { GDP } \\
\mathbf{g}\end{array}$} & \multirow{2}{*}{$\begin{array}{c}\text { CR } \\
\mathrm{g}\end{array}$} & \multirow[t]{2}{*}{ CA } & \multirow{2}{*}{$\begin{array}{c}\text { TCE } \\
\% \mathrm{dia}^{-1}\end{array}$} \\
\hline Tratamentos & Repetições & & & & & & \\
\hline T1 (0 mg) & 1 & 94,70 & 716,65 & 621,92 & 575,22 & 0,925 & 3,21 \\
\hline T1 & 2 & 128,90 & 724,54 & 595,64 & 593,60 & 0,997 & 2,74 \\
\hline T1 & 3 & 108,20 & 731,84 & 623,64 & 588,01 & 0,943 & 3,03 \\
\hline T1 & 4 & 151,90 & 761,56 & 609,66 & 601,08 & 0,986 & 2,56 \\
\hline T2 (50 mg) & 1 & 113,00 & 651,39 & 538,36 & 530,32 & 0,985 & 2,78 \\
\hline T2 & 2 & 144,40 & 733,63 & 589,23 & 584,41 & 0,992 & 2,58 \\
\hline T2 & 3 & 141,90 & 747,50 & 605,60 & 577,88 & 0,954 & 2,64 \\
\hline $\mathbf{T} 2$ & 4 & 151,20 & 743,89 & 592,69 & 579,14 & 0,977 & 2,53 \\
\hline T3 (100 mg) & 1 & 103,10 & 694,66 & 591,56 & 563,70 & 0,953 & 3,03 \\
\hline T3 & 2 & 160,60 & 803,18 & 642,58 & 587,71 & 0,915 & 2,56 \\
\hline T3 & 3 & 147,60 & 743,32 & 595,76 & 592,47 & 0,994 & 2,57 \\
\hline T3 & 4 & 105,20 & 728,32 & 623,12 & 580,57 & 0,932 & 3,07 \\
\hline T4 (150 mg) & 1 & 125,70 & 730,42 & 604,72 & 565,47 & 0,935 & 2,79 \\
\hline T4 & 2 & 136,70 & 740,85 & 604,15 & 574,61 & 0,951 & 2,68 \\
\hline T4 & 3 & 123,80 & 708,35 & 584,55 & 559,67 & 0,957 & 2,77 \\
\hline T4 & 4 & 156,60 & 774,13 & 617,53 & 583,91 & 0,946 & 2,54 \\
\hline T5 (200 mg) & 1 & 118,80 & 705,60 & 586,80 & 538,75 & 0,918 & 2,83 \\
\hline T5 & 2 & 133,10 & 716,65 & 583,55 & 570,56 & 0,978 & 2,67 \\
\hline T5 & 3 & 152,50 & 781,28 & 628,78 & 603,11 & 0,959 & 2,59 \\
\hline T5 & 4 & 150,70 & 754,58 & 603,88 & 597,49 & 0,989 & 2,56 \\
\hline T6 (250 mg) & 1 & 99,30 & 640,63 & 541,32 & 564,01 & 1,042 & 2,96 \\
\hline T6 & 2 & 165,30 & 725,72 & 560,43 & 560,27 & 1,000 & 2,35 \\
\hline T6 & 3 & 150,00 & 751,65 & 601,65 & 562,13 & 0,934 & 2,56 \\
\hline T6 & 4 & 190,80 & 829,34 & 638,54 & 592,65 & 0,928 & 2,33 \\
\hline T7 (300 mg) & 1 & 123,30 & 730,43 & 607,13 & 561,85 & 0,925 & 2,82 \\
\hline $\mathbf{T 7}$ & 2 & 150,40 & 720,87 & 570,47 & 564,42 & 0,989 & 2,49 \\
\hline T7 & 3 & 142,20 & 775,22 & 633,02 & 582,99 & 0,921 & 2,69 \\
\hline T7 & 4 & 127,80 & 785,48 & 657,68 & 580,17 & 0,882 & 2,88 \\
\hline T8 (500 mg) & 1 & 129,40 & 696,78 & 567,38 & 551,38 & 0,972 & 2,67 \\
\hline T8 & 2 & 136,90 & 756,22 & 619,32 & 565,53 & 0,913 & 2,71 \\
\hline T8 & 3 & 137,60 & 779,82 & 642,22 & 582,29 & 0,907 & 2,75 \\
\hline T8 & 4 & 140,20 & 753,39 & 613,19 & 574,17 & 0,936 & 2,67 \\
\hline T9 (700 mg) & 1 & 132,00 & 761,25 & 629,25 & 565,65 & 0,899 & 2,78 \\
\hline T9 & 2 & 124,70 & 762,26 & 637,56 & 580,60 & 0,911 & 2,87 \\
\hline T9 & 3 & 156,60 & 777,35 & 620,75 & 581,49 & 0,937 & 2,54 \\
\hline T9 & 4 & 119,90 & 784,65 & 664,75 & 586,48 & 0,882 & 2,98 \\
\hline T10 (900 mg) & 1 & 114,10 & 748,87 & 634,77 & 575,81 & 0,907 & 2,99 \\
\hline T10 & 2 & 107,40 & 749,34 & 641,94 & 585,15 & 0,912 & 3,08 \\
\hline T10 & 3 & 157,70 & 754,16 & 596,46 & 588,26 & 0,986 & 2,48 \\
\hline T10 & 4 & 144,80 & 738,93 & 594,13 & 568,37 & 0,957 & 2,59 \\
\hline
\end{tabular}

Médias das unidades experimentais (gaiolas). 
Tabela 2. Médias dos parâmetros de desempenho - valores médios por indivíduo

\begin{tabular}{|c|c|c|c|c|c|c|c|}
\hline \multicolumn{2}{|c|}{$\begin{array}{c}\text { Parâmetros de } \\
\text { desempenho }\end{array}$} & \multirow{2}{*}{$\begin{array}{c}\text { PI } \\
\text { g peixe }^{-1}\end{array}$} & \multirow{2}{*}{$\begin{array}{c}\text { PF } \\
\text { g peixe }^{-1}\end{array}$} & \multirow{2}{*}{$\begin{array}{c}\text { GDP } \\
\text { g peixe }^{-1}\end{array}$} & \multirow{2}{*}{$\begin{array}{c}\text { CR } \\
\text { g peixe }^{-1}\end{array}$} & \multirow[t]{2}{*}{$\mathbf{C A}$} & \multirow{2}{*}{$\frac{\text { TCE }}{\text { \% } \text { dia }^{-1}}$} \\
\hline Tratamentos & Repetições & & & & & & \\
\hline T1 (0 mg) & 1 & 6,77 & 51,19 & 44,42 & 41,09 & 0,925 & 3,21 \\
\hline T1 & 2 & 8,59 & 48,30 & 39,71 & 39,57 & 0,997 & 2,74 \\
\hline $\mathrm{T} 1$ & 3 & 7,21 & 48,79 & 41.58 & 39,20 & 0,943 & 3,03 \\
\hline T1 & 4 & 10,13 & 50,77 & 40,64 & 40,07 & 0,986 & 2,56 \\
\hline T2 (50 mg) & 1 & 8,07 & 46,53 & 38,45 & 37,88 & 0,985 & 2,78 \\
\hline T2 & 2 & 9,63 & 48,91 & 39,28 & 38,96 & 0,992 & 2,58 \\
\hline $\mathbf{T 2}$ & 3 & 9,46 & 49,83 & 40,37 & 38,53 & 0,954 & 2,64 \\
\hline $\mathbf{T} 2$ & 4 & 10,08 & 49,59 & 39,51 & 38,61 & 0,977 & 2,53 \\
\hline T3 (100 mg) & 1 & 6,87 & 46,31 & 39,44 & 37,58 & 0,953 & 3,03 \\
\hline T3 & 2 & 10,71 & 53,55 & 42,84 & 39,18 & 0,915 & 2,56 \\
\hline T3 & 3 & 10,54 & 53,09 & 42,55 & 42,32 & 0,994 & 2,57 \\
\hline T3 & 4 & 7,01 & 48,55 & 41,54 & 38,70 & 0,932 & 3,07 \\
\hline T4 (150 mg) & 1 & 8,38 & 48,69 & 40,31 & 37,70 & 0,935 & 2,79 \\
\hline $\mathbf{T 4}$ & 2 & 9,11 & 49,39 & 40,28 & 38,31 & 0,951 & 2,68 \\
\hline T4 & 3 & 8,25 & 47,22 & 38,97 & 37,31 & 0,957 & 2,77 \\
\hline T4 & 4 & 10,44 & 51,61 & 41,17 & 38,93 & 0,946 & 2,54 \\
\hline T5 (200 mg) & 1 & 7,43 & 44,10 & 36,68 & 33,67 & 0,918 & 2,83 \\
\hline T5 & 2 & 8,87 & 47,78 & 38,90 & 38,04 & 0,978 & 2,67 \\
\hline T5 & 3 & 10,17 & 52,09 & 41,92 & 40,21 & 0,959 & 2,59 \\
\hline T5 & 4 & 10,05 & 50,31 & 40,26 & 39,83 & 0,989 & 2,56 \\
\hline T6 (250 mg) & 1 & 7,09 & 45,76 & 38,67 & 40,29 & 1,042 & 2,96 \\
\hline T6 & 2 & 11,81 & 51,84 & 40,03 & 40,02 & 1,000 & 2,35 \\
\hline T6 & 3 & 10,71 & 53,69 & 42,98 & 40,15 & 0,934 & 2,56 \\
\hline T6 & 4 & 12,72 & 55,29 & 42,57 & 39,51 & 0,928 & 2,33 \\
\hline T7 (300 mg) & 1 & 8,22 & 48,70 & 40,48 & 37,46 & 0,925 & 2,82 \\
\hline T7 & 2 & 10,03 & 48,06 & 38,03 & 37,63 & 0,989 & 2,49 \\
\hline T7 & 3 & 9,48 & 51,68 & 42,20 & 38,87 & 0,921 & 2,69 \\
\hline T7 & 4 & 8,52 & 52,37 & 43,85 & 38,68 & 0,882 & 2,88 \\
\hline T8 (500 mg) & 1 & 8,63 & 46,45 & 37,83 & 36,76 & 0,972 & 2,67 \\
\hline T8 & 2 & 9,13 & 50,41 & 41,29 & 37,70 & 0,913 & 2,71 \\
\hline T8 & 3 & 9,17 & 51,99 & 42,81 & 38,82 & 0,907 & 2,75 \\
\hline T8 & 4 & 9,35 & 50,23 & 40,88 & 38,28 & 0,936 & 2,67 \\
\hline T9 (700 mg) & 1 & 8,25 & 47,58 & 39,33 & 35,35 & 0,899 & 2,78 \\
\hline T9 & 2 & 8,31 & 50,82 & 42,50 & 38,71 & 0,911 & 2,87 \\
\hline T9 & 3 & 10,44 & 51,82 & 41,38 & 38,77 & 0,937 & 2,54 \\
\hline T9 & 4 & 7,99 & 52,31 & 44,32 & 39,10 & 0,882 & 2,98 \\
\hline T10 (900 mg) & 1 & 7,61 & 49,92 & 42,32 & 38,39 & 0,907 & 2,99 \\
\hline T10 & 2 & 7,16 & 49,96 & 42,80 & 39,01 & 0,912 & 3,08 \\
\hline T10 & 3 & 10,51 & 50,28 & 39,76 & 39,22 & 0,986 & 2,48 \\
\hline T10 & 4 & 9,65 & 49,26 & 39,61 & 37,89 & 0,957 & 2,59 \\
\hline
\end{tabular}

Médias dos peixes de cada unidade experimental (gaiola). 
Tabela 3. Valores dos parâmetros hematológicos obtidos durante o experimento

\begin{tabular}{|c|c|c|c|c|c|c|}
\hline \multicolumn{2}{|c|}{ Parâmetros hematológicos } & \multirow{2}{*}{$\begin{array}{c}G V \\
10^{6} \mu L^{-1}\end{array}$} & \multirow{2}{*}{$\begin{array}{c}\text { HCT } \\
\%\end{array}$} & \multirow{2}{*}{$\begin{array}{c}\mathrm{VCM} \\
\mathrm{\mu m}^{3}\end{array}$} & \multirow{2}{*}{$\begin{array}{c}\mathbf{H b} \\
\mathrm{g} \mathrm{dL}^{-1}\end{array}$} & \multirow{2}{*}{$\begin{array}{c}\text { GB } \\
\text { células } \mu \mathrm{L}^{-1}\end{array}$} \\
\hline Tratamentos & Repetições & & & & & \\
\hline T1 (0 mg) & 1 & 2,28 & 29,9 & 131,1 & 11,0 & 12.000 \\
\hline T1 & 2 & 1,97 & 27,4 & 139,1 & 11,1 & 10.000 \\
\hline T1 & 3 & 2,21 & 29,8 & 134,8 & 10,5 & 9.000 \\
\hline T1 & 4 & 2,05 & 27,3 & 133,2 & 11,7 & 11.000 \\
\hline T2 (50 mg) & 1 & 2,44 & 29,4 & 120,5 & 10,7 & 20.000 \\
\hline $\mathbf{T} 2$ & 2 & 1,85 & 24,9 & 134,6 & 10,4 & 5.000 \\
\hline $\mathbf{T 2}$ & 3 & 2,20 & 30,3 & 137,7 & 11,8 & 9.000 \\
\hline T2 & 4 & 2,07 & 28,3 & 136,7 & 10,5 & 27.000 \\
\hline T3 (100 mg) & 1 & 2,04 & 27,5 & 134,8 & 10,6 & 15.000 \\
\hline T3 & 2 & 2,96 & 45,8 & 154,7 & 10,1 & 4.000 \\
\hline T3 & 3 & 1,98 & 27,5 & 138,9 & 11,2 & 8.000 \\
\hline T3 & 4 & 1,92 & 27,5 & 143,2 & 11,5 & 11.000 \\
\hline T4 (150 mg) & 1 & 2,09 & 27,5 & 131,6 & 11,4 & 16.000 \\
\hline T4 & 2 & 3,74 & 48,4 & 129,4 & 12,5 & 9.000 \\
\hline T4 & 3 & 2,11 & 28,1 & 133,2 & 11,7 & 16.000 \\
\hline $\mathbf{T 4}$ & 4 & 1,93 & 29,7 & 153,9 & 10,9 & 23.000 \\
\hline T5 (200 mg) & 1 & 1,81 & 26,7 & 147,5 & 10,1 & 9.000 \\
\hline T5 & 2 & 2,19 & 31,2 & 142,5 & 12,5 & 11.000 \\
\hline T5 & 3 & 2,16 & 31,0 & 143,5 & 11,6 & 8.000 \\
\hline T5 & 4 & 2,20 & 32,7 & 148,6 & 11,0 & 12.000 \\
\hline T6 (250 mg) & 1 & 2,42 & 31,9 & 131,8 & 12,0 & 20.000 \\
\hline T6 & 2 & 2,14 & 29,6 & 138,3 & 11,8 & 12.000 \\
\hline T6 & 3 & 2,22 & 30,3 & 136,5 & 12,4 & 5.000 \\
\hline T6 & 4 & 1,78 & 26,8 & 150,6 & 9,6 & 22.000 \\
\hline T7 (300 mg) & 1 & 1,98 & 28,8 & 145,5 & 10,4 & 16.000 \\
\hline T7 & 2 & 1,86 & 29,9 & 160,8 & 9,6 & 19.000 \\
\hline T7 & 3 & 2,12 & 30,3 & 142,9 & 11,7 & 14.000 \\
\hline $\mathbf{T} 7$ & 4 & 1,83 & 24,2 & 132,2 & 10,4 & 17.000 \\
\hline T8 (500 mg) & 1 & 2,18 & 31,8 & 145,9 & 11,4 & 10.000 \\
\hline T8 & 2 & 1,94 & 26,5 & 136,6 & 10,6 & 15.000 \\
\hline T8 & 3 & 2,02 & 27,6 & 136,6 & 10,5 & 14.000 \\
\hline T8 & 4 & 2,02 & 31,0 & 153,5 & 8,6 & 26.000 \\
\hline T9 (700 mg) & 1 & 2,16 & 29,8 & 138,0 & 11,1 & 7.000 \\
\hline T9 & 2 & 2,07 & 30,0 & 144,9 & 11,5 & 9.000 \\
\hline T9 & 3 & 2,05 & 29,9 & 145,9 & 11,6 & 7.000 \\
\hline T9 & 4 & 2,04 & 27,2 & 133,3 & 10,7 & 18.000 \\
\hline T10 (900 mg) & 1 & 1,92 & 26,5 & 138,0 & 10,6 & 23.000 \\
\hline T10 & 2 & 2,04 & 27,0 & 132,4 & 11,0 & 6.000 \\
\hline T10 & 3 & 1,73 & 24,3 & 140,5 & 9,9 & 5.000 \\
\hline T10 & 4 & 1,38 & 20,9 & 151,4 & 8,3 & 19.000 \\
\hline
\end{tabular}

